NBER WORKING PAPER SERIES

\title{
THE WINNERS AND LOSERS OF IMMIGRATION: EVIDENCE FROM LINKED HISTORICAL DATA
}

\author{
Joseph Price \\ Christian vom Lehn \\ Riley Wilson \\ Working Paper 27156 \\ http://www.nber.org/papers/w27156 \\ NATIONAL BUREAU OF ECONOMIC RESEARCH \\ 1050 Massachusetts Avenue \\ Cambridge, MA 02138 \\ May 2020
}

We are grateful to Jacob Van Leeuwen for excellent research assistance with this project. We thank Leah Boustan, Michael Clemens, Jeff Denning, Brigham Frandsen, Jongkwan Lee, Dave Sims, Marco Tabellini, and Abigail Wozniak for useful comments and feedback. The views expressed herein are those of the authors and do not necessarily reflect the views of the National Bureau of Economic Research.

NBER working papers are circulated for discussion and comment purposes. They have not been peer-reviewed or been subject to the review by the NBER Board of Directors that accompanies official NBER publications.

(C) 2020 by Joseph Price, Christian vom Lehn, and Riley Wilson. All rights reserved. Short sections of text, not to exceed two paragraphs, may be quoted without explicit permission provided that full credit, including $\odot$ notice, is given to the source. 
The Winners and Losers of Immigration: Evidence from Linked Historical Data

Joseph Price, Christian vom Lehn, and Riley Wilson

NBER Working Paper No. 27156

May 2020

JEL No. J21,J31,J61,J62,N32

\begin{abstract} workers are "winners."

Joseph Price

Department of Economics

Riley Wilson

Brigham Young University

435 CTB

Department of Economics

162 FOB

Provo, UT 84602

Brigham Young University

and NBER

joseph_price@byu.edu

Provo, Utah 84602

riley_wilson@byu.edu

Christian vom Lehn

Brigham Young University

435 Crabtree Building

Provo, UT 84602

cvomlehn@byu.edu
\end{abstract}

Using recent innovations in linking historical U.S. Census data, we study the economic impacts of immigration on natives, including their geographic migration response. We find that the arrival of foreign immigrants significantly increases both native out-migration and in-migration. Accounting for this selective geographic migration, we find smaller economic impacts of immigration for native workers than previous work, including no positive impact on worker incomes. We present evidence of significant "losers" from increased immigration, namely workers who appear to be displaced by immigrant labor and move out of their local labor market, whereas the workers who remain see significant benefits. We also find that younger and lowerskilled workers are "losers" from increased immigration, whereas older and higher-skilled

A data appendix is available at http://www.nber.org/data-appendix/w27156 


\section{Introduction}

In spite of a large amount of research on the topic, there yet remains substantial debate about the economic impact of immigration on natives. ${ }^{1}$ Many papers study the impact of immigration on natives at the local labor market level, contrasting average labor market outcomes in areas exposed to higher levels of immigration with those with less immigration. Several recent papers use this approach with historical U.S. data from the early $20^{\text {th }}$ century, when changes in global conditions and U.S. immigration policy generated substantial changes in immigrant inflows to the United States (Sequeira et al. (2019), Ager and Hansen (2017), Tabellini (2020), and Abramitzky et al. (2019)). These papers find substantial (and in some cases, surprising) economic benefits to natives from immigration. However, there are two key limitations to this approach. First, local labor market analysis is best at identifying average treatment effects, but is less powerful for understanding heterogeneity in individual level impacts. Second, local labor market estimates of the economic impacts of immigration will only accurately identify the average treatment effect for the original native population if there is not selective migration in response to changes in immigration. ${ }^{2}$ Given the high native migration rates of U.S. natives in the early $20^{\text {th }}$ century and the fact that local labor market comparisons are made across decades, this suggests caution in making this assumption.

In this paper, we study the economic impacts of immigration on natives, including the native migration response, using a newly constructed panel of linked census records in the United States from 1910-1930. We use recent linking innovations from Price et al. (2019), which combine a rich genealogical database and machine learning to link Census records across time. This allows us to follow over 4 million men matched between 1910 and 1920 or 1920 and 1930 (approximately 40 percent of the target population). With the panel structure of the data, we are able to uncover more precisely the economic impacts of immigration for outcomes such as internal migration, income, employment, and occupational mobility, while accounting for selective migration by natives. We are also able to estimate the heterogeneous treatment effects across individuals differentiated by age and skill to determine who are the relative "winners" and the "losers" from immigration.

\footnotetext{
${ }^{1}$ For partial summaries of this large literature, see Borjas (1999), Card (2005), Card (2009), Kerr and Kerr (2011), Lewis and Peri (2015), Peri (2016) and Dustmann, Schoenberg, and Stuhler (2016).

2 This point was given substantial attention in earlier work in the literature on immigration, such as Borjas, Freeman and Katz (1996, 1997), Card and DiNardo (2000), Card (2001), and Borjas (2006).
} 
To estimate the impact of immigration on economic outcomes, we draw upon the estimation framework of Tabellini (2020), who studies the local labor market impacts of immigration using a panel of large U.S. cities over this same time period. As in Tabellini (2020), we focus on the city-level fraction of the population that recently immigrated to the United States. This fraction is likely to be correlated with economic outcomes for a variety reasons, such as immigrants choosing to settle in more prosperous regions of the country. To generate exogenous variation in the fraction of the population who are immigrants, as in Tabellini (2020), we leverage the pre-existing relationship between immigrant settlement patterns across cities, as it is well established that immigrants tend to settle in areas where there are many former immigrants of the same nationality (for example, see Card (2001)). Similar to Tabellini (2020), we find that our results are also robust to using variation in immigration generated by U.S. immigration quotas in the 1920s and the immigration restrictions of World War I.

Using our individual panel data, we find, similar to the existing literature, that increases in immigration increased labor force participation and native incomes when averaged up to the local labor market level. However, at the individual level, accounting for the fact that native workers may have moved away in response to immigration, we find different results. Workers who initially lived in cities where immigration flows did see increases in labor force participation, but no income gains. We also show that there is an "insurance effect" from increased immigration, as workers in cities with increased immigration were less likely to make an occupational switch to a lower-paying occupation. The key reason for the difference in our findings is that we observe that increased immigration generates substantial out-migration by natives and these out-migrants tend to see worse outcomes.

While our findings for the average impact of immigration suggests weakly positive results for the original residents of local labor markets, we find substantial heterogeneity in how workers of different age and skill levels are impacted by increased immigration. In response to increased immigration, younger workers move away at higher rates, are more likely to enter the labor force and more likely to experience income losses. Indeed, we show that increases in labor force participation are exclusively concentrated on young workers under the age of 24, likely accelerating their entry into the labor market, and that there is no significant impact for primeaged workers. We also find that lower skilled workers are similarly more likely to move out and observe income losses in response to increases in immigration. In contrast, older and higher- 
skilled workers are less likely to move and more likely to see income gains from immigration. Thus, we conclude that younger and lower skilled workers are the relative "losers" from immigration and older and higher skilled workers are the relative "winners." 3

We further show that economic losses from immigration are larger for those workers who move away from their original local labor market in response to increased immigration. Although we cannot attach a causal interpretation to these effects, as migration is an endogenous response to immigration, we view this as evidence of a significant displacement effect for certain workers. ${ }^{4}$ We provide supporting evidence for this argument along two dimensions. First, we show that workers initially in occupations that immigrants in this time period were commonly employed in were much more likely to move out of their cities in response to increases in immigration. Second, an alternative story to the displacement argument we present is that some workers may move away for taste-based responses to immigration, such as prejudice. However, we show that workers who moved away from cities experiencing increased immigration did not move to areas with lower levels of immigrants, suggesting that these workers' relocation decisions does not reflect an aversion to living in areas with high immigrant populations.

Finally, we show that in addition to a substantial out-migration of native workers in response to increased immigration, there was also a substantial in-migration of native workers. These move-ins are negatively selected, with lower income and skill levels relative to the rest of population, including workers moving out. However, workers who move in see substantial income gains with migration. This suggests that the difference in local labor market and individual results is not driven by large changes in the composition of workers over initial observable characteristics, though are in part driven by selection on potential losses/gains from migration. These income gains and losses for move-ins and move-outs (respectively), along with income gains for workers who stayed, can account for the positive income gains observed at the local labor market level.

\section{Related Literature}

\footnotetext{
${ }^{3}$ In Online Appendix C, we also show that workers with parents born in the U.S. fare worse in terms of labor force participation than workers with at least one parent who is an immigrant and that black men face much worse labor market outcomes from immigration as well (similar to findings in Ager and Hansen (2017)). Thus, these two groups are also among the particular "losers" of increased immigration.

${ }^{4}$ We argue in Section 4.5 that these losses might be a lower bound since workers who move are often positively selected (Borjas et al. (1992), Dahl (2002)).
} 
Our paper naturally relates to the vast literature on the economic impacts of immigration, especially those papers assessing the internal migration response of natives to changes in immigrant flows. Early work such as Card and DiNardo (2000), Card (2001), and Borjas (2006) debated whether or not there was a "skating rink" effect of immigration, with new immigrants pushing out natives, "knocking them off the ice.” While the presence of such an effect was debated in these papers and subsequent work by Peri (2011) and Peri and Sparber (2011), these studies are all limited by their inability to directly observe individuals over time, and thus are limited to studying net flows of individuals by skill group. In contrast, we are able to assess the gross flows of migration in response to immigration and estimate the effects of immigration for those individuals who actually migrate away. With this data, we find the presence of a significant “skating rink" effect for young and low-skilled workers in cities with increased immigration in the early $20^{\text {th }}$ century.

The most closely related papers to our work are several recent papers studying the impact of immigration on native workers in the late $19^{\text {th }}$ and early $20^{\text {th }}$ century United States (Sequeira et al. (2019), Ager and Hansen (2017), Tabellini (2020), Abramitzky et al. (2019)). A common thread in these papers is that they generally find modest to substantially positive impacts of increased immigration at the local labor market level, a finding we reproduce when we aggregate our individual level data to the local labor market level. Our findings are also consistent with those of Abramitzky et al. (2019), who show a positive relationship between worker incomes and immigration in a linked sample of workers. The sample considered by Abramitzky et al. (2019) is of the original residents who stayed and the new move-ins to the region and combines both the changes in incomes for these workers as well as the changes in selection of these workers. We show that our findings for stayers are consistent with their findings, and that once we account for selection, our findings for new move-ins are also consistent. The key difference between our results is that we include workers who move away from their original labor market in our estimates, and these workers observe substantial income losses with increased immigration.

Our paper also relates to two studies on immigration using linked panel data in Europe, Cattaneo et al. (2015) and Foged and Peri (2016). Foged and Peri (2016) use linked panel data from Denmark to estimate the dynamic impacts of immigration; however, unlike the US, internal migration in Denmark is extremely low and thus plays virtually no role in the economic response to immigration. Cattaneo et al. (2015) also consider a panel of European workers, but do not 
study the geographic mobility of these workers in response to immigration. They do, however, find evidence that increases in immigration lead to upward occupational mobility, with natives switching to occupations with higher pay, and some evidence that the incidence of downward occupational switching declined. We find evidence of the latter effect, a reduction in downward occupational switching, but we find no evidence for increased upward occupational mobility on average, though we do find evidence of this for higher skilled workers. In contrast, we find that upward occupational mobility was reduced for young and low-skilled workers, and that workers moving out saw reduced upward occupational mobility and no change in the probability of downward occupational mobility

We interpret the average reduced incidence of downward occupational switching as an insurance effect, reducing labor market risk for native workers. This finding has some similarities with recent findings from Cadena and Kovak (2016). They find immigration by lowskilled Mexican immigrants during the Great Recession was highly sensitive to local labor demand conditions, and thus equilibrated employment risk for native workers across local labor markets. While their work focuses on the migration patterns of immigrants in generating reduced risk, our finding of reduced downward occupational switches similarly represents some stabilization of local economic conditions for natives. The fact that this insurance effect is not observed for workers who move away from the local labor market further supports the idea that the effect operates through the channel of local demand shocks.

Recently, Lee et al. (2019) use linked U.S. data from 1930-1940 to study the impact of Mexican repatriation between 1929-1934 and also find that selective out-migration and inmigration can lead to substantial differences in labor market outcomes observed at the individual and local labor market levels. Like Lee et al. (2019), we also find that there is attenuation of results at the individual level compared to the local labor market level, particularly in changes in income, and our findings are consistent with their finding that reductions in immigration led to increased occupational downgrading and declines in employment. In contrast, we find that the differences in local labor market and individual results are primarily driven by differential effects for movers and stayers and not changes in composition. Relative to their work, we also consider how these effects vary across age and skill.

Also related to our paper is work by Boustan et al. (2010), who study the causal impact of migration on local labor markets during the Great Depression. Their focus is not specifically on 
immigration, but on cross-city native migration and how this impacted local labor markets. They find, similar to us, that increased migration had little impact on incomes for existing residents, but did generate substantial out-migration of original residents. An important difference between our study and theirs is that they measure cross-city migration using information reported retrospectively in 1940 about an individual's prior residence and do not have information on individual characteristics prior to the move. With our linked panel data, we are uniquely able to identify both individual changes over time in response to immigration (occupation, employment, income) and which populations were more affected by changes in immigration.

We recognize that our findings regarding which workers are winners and losers of immigration may depend on the particular waves of immigration that took place during this period. For example, using aggregated data from the American Community Survey, Wozniak and Murray (2012) provide evidence that local labor market immigration flows from 2000-2010 impacted year to year population flows and employment rates of high-skilled workers more than low-skilled workers. By focusing on individual outcomes, our work sheds light on heterogeneous individual outcomes that are not observable in aggregated data. As a result, our findings highlight the importance of using individual data to understand the full distributional economic impacts of immigration.

\section{Data}

Our analysis uses full count U.S. Census data from the years 1910, 1920 and 1930, originally obtained from the genealogical website FamilySearch and then merged to the data produced by the genealogical website Ancestry and IPUMS (Ruggles et al. (2019)). ${ }^{5} \mathrm{We}$ primarily focus on males ages 15-65 for our analysis, as men younger than 15 and older than 65 have very low rates of labor force participation. ${ }^{6}$ We omit women from our baseline results because female labor force participation rates are generally very low during this period and because linking Census records across time for women often results in much lower match rates.

\footnotetext{
${ }^{5}$ As described below, obtaining the full count data from FamilySearch initially allows us improved ability to link individual records across time. When linking this data to the full count data that Ancestry and IPUMS jointly produce, we observe match rates of $98 \%$, so there is very little loss of data from this procedure.

${ }^{6}$ Further, the universe of labor market survey questions for Census the years 1910-1930 omits individuals under the age of 16, so we cannot observe the labor market patterns for these individuals.
} 
However, the linking algorithms we use give us a substantial sample of women over this time period, and in Online Appendix C, we do report results for women ages 15-65. ${ }^{7}$

To relate to existing work showing the economic impacts of immigration, we restrict our sample to focus on residents of U.S. cities which had a population of at least 30,000 in each of the years 1910, 1920 and 1930 and which had at least some European immigrants, consistent with Tabellini (2020). ${ }^{8}$ The requirement that cities have at least some European immigrants is consistent with the observation that a large fraction of the changes in immigration over this time period were driven by changes in immigrants coming from Europe. Though we do not need to restrict our attention to the same set of cities as Tabellini (2020), since we ultimately focus on a smaller linked sample of the population and include in our study the distribution of treatment effects across age and skill, focusing on cities with these large populations ensures that we have sufficient power to estimate the impacts of immigration for the populations we study. There are 180 cities that satisfy these criteria, however for consistency with Tabellini (2020), we omit the cities New Bedford, MA and Sacramento, CA. We show, however, in Online Appendix B that our results are robust to including these cities. ${ }^{9}$ We provide a list of the 180 cities we study in Online Appendix A.

Central to our analysis is our ability to follow individual workers over time across census waves. To observe changes in individual-level outcomes, including native migration, we link individuals across census waves using the methods developed by Abramitzky et al. (2014) and Price et al. (2019). This process combines both rule-based methods and links based on a machine learning algorithm. The key innovation of this process is that it employs a massive training set that is drawn from user-generated links of the genealogical platform at familysearch.org. These links are generally very accurate because users on this platform work on their ancestors' genealogy and frequently have access to large amounts of information when linking ancestors to census records. Price et al. (2019) utilize this large user created dataset to create training data with a large ground truth set. The key observable characteristics used to link individuals in this

\footnotetext{
${ }^{7}$ The linking methodology we use, taken from Price et al. (2019), actually generates higher match rates for women than many common linking algorithms, and thus we are ultimately able to generate a sufficiently high match rate to obtain meaningful results just for women.

${ }^{8}$ Tabellini (2020) imposes these restrictions on city size because much of his analysis also considers the political impacts of immigration, and these are only observable for cities of sufficient size.

${ }^{9}$ Tabellini (2020) omits these cities because they have missing employment data for the year 1920 in his data.
} 
machine learning algorithm are race, gender, birth year, name, family structure, birthplace and place of residence. ${ }^{10}$

As our study uses historical Census data, it is worth commenting on how we measure key labor market outcomes such as labor force participation and workers’ income. In our data, labor force participation is measured differently than current standard practices, implemented since the 1940 Census. A worker is considered in the labor force if they report a "gainful occupation.” As a result, though we will study workers' labor force participation as one of our outcomes, measures of labor force participation in our data are more likely to correspond to what we would now consider employment instead of labor force participation. ${ }^{11}$

Prior to the 1940 Census, there were no direct measures of a worker's income, so we follow existing literature and use imputed measures of income based on their occupation, called an “occupation score.” In our data, we are able to observe occupation codes for each worker, assigned by IPUMS on the basis of the 1950 occupation coding system. Workers' income is then imputed using the median income in 1950 paid to that occupation, and is measured in hundreds of 1950 dollars.

While using occupation scores is a common approach to measuring income in historical Census data, it is naturally subject to limitations. A key limitation is that a workers' income can only change when they experience an occupational switch, and thus income changes in our data will be intrinsically tied to occupational switching. Another limitation of this approach to measuring income is that it requires that the workers' contemporary occupation be successfully mapped into a corresponding occupation measured in the year 1950. In our data, most workers' occupations have been easily mapped to 1950 occupation codes. However, there are a number of observations in the historical Census data for which IPUMS has not yet successfully assigned a corresponding 1950-based occupation. In our baseline specifications, we drop these "not yet classified” observations from our sample, however we show in Online Appendix B that our non-

\footnotetext{
${ }^{10}$ Our algorithm does not restrict matching on the basis of original location of residence, though uses this as a feature to improve matching. As a result, however, our algorithm is likely to understate the overall move rate for workers, which we report to be fairly high in Table 2.

${ }^{11}$ It is not immediately evident, however, as to whether workers who report a gainful occupation need be employed. To the extent that part of a worker's identity is their occupation, they may report an occupation even if they are not presently employed. A more standard measure of employment is available in 1910 and 1930 but not in 1920.
} 
income results are robust to including them, as are our results for income using alternative imputation approaches.

We also rely on occupation data both in studying occupational mobility of workers and how workers are impacted differently with changes in immigration. We use a worker's initial occupation as a proxy for "skill” as there are no measures of educational attainment in our data. For parsimony, when using occupation as a proxy for worker skill, we focus on a narrow set of nine one-digit occupations, such as farmer, salesman, manager, and professional workers, ranked by their average occupation score. We also use these one digit occupations when assessing the probability that a worker switched to reduce the incidence of spurious occupational switching because of small differences in coding of worker responses regarding their occupations. We provide a list of the detailed occupation codes corresponding to each one digit code in Online Appendix A, along with their average occupation score.

We present summary statistics for our final estimation sample, split by Census waves, in Table 1 and along with a comparable sample from the raw, unlinked Census data. Using the linking methodology of Price et al. (2019) for the sample of men between the ages of 15-65 residing at any point in any of the 178 cities we study who never report a "not yet classified" occupation, we are able to link roughly 1.8 million records between 1910 and 1920 and 2.4 million records between 1920 and 1930, giving us a total sample of roughly 4.2 million linked pairs. Using these same sample criteria without any linking would imply 4.7 million observations in 1910 and 5.8 million observations in 1920. This implies a match rate of 38-41\% of all eligible individuals originally observed in either the 1910 or 1920 Census. $^{12}$

Comparing the average characteristics of the full sample and the linked sample, we find that our linked sample compares favorably with the full sample. ${ }^{13}$ Perhaps the most notable differences between the full sample and our linked sample is that men in our linked data are more likely to be white and more likely to be married. These differences are perhaps unsurprising given a well-known difficulty in linking black men in this period of time and given

\footnotetext{
${ }^{12}$ This match rate is slightly lower than those reported in Price et al. (2019) for two main reasons. First, Price et al. (2019) report match rates on the basis of potential matches, adjusted for factors such as under-enumeration in the Census. Second, part of the high match rates observed in Price et al. (2019) come from the use of place of residence information to link individuals over time. However, this added information is less valuable for large cities, as we study in our sample, since there are many more records for each city.

${ }^{13}$ We do not report t-tests for the differences of means for the linked and full samples, mainly because given our large sample size, even very small differences in means are statistically significant, even if not economically significant.
} 
that our linking procedure uses family structure as an input to the machine learning algorithm; as a result, married men are easier to link and thus slightly overrepresented in our sample.

With our linked sample, we are able to compute individual 10 year out-migration rates, for which we report averages in Table 2. We also report out-migration rates by 10 year age groups and for 1 digit occupation groups, in ascending order of skill (as measured by average occupation scores). Importantly, we observe that between 1910-1920 and 1920-1930, outmigration rates are particularly high, at least 30\%. ${ }^{14}$ Perhaps unsurprisingly, we also observe that out-migration rates are higher for younger and lower skilled workers. These high rates of native mobility suggest that migration flows are large enough over this time period to potentially confound local labor market estimates of the worker-level impacts of immigration if there is a selective migration response.

\section{Empirical Approach}

We consider both local labor market level specifications and individual specifications in our analysis. We consider results from local labor market specifications to show that our data produce comparable results to existing literature when aggregated up to the local labor market level. An important characteristic of our local labor market regressions is that treatment is assigned to individuals on the basis of their current residence. As a result, differences in local labor market outcomes over time represent both changes for individuals who originally resided in that labor market and a change in the set of individuals residing in that labor market.

\subsection{Estimating Equations}

For local labor market specifications, we consider a first-differences baseline specification, given by:

$$
\Delta Y_{c s t}=\beta_{1} \Delta \text { FracImmig } c t+\Gamma_{s t}+\varepsilon_{c s t}
$$

where $\Delta Y_{c t}$ is the change in the labor market outcome of interest for city $c$ in state $s$ between $t$ and $t-10$ (where $t$ is either 1920 or 1930), the key independent variable is the change in the percent of the population who are immigrants in that city and time period ( $\Delta$ FracImmig $\left.g_{c t}\right)$, and

\footnotetext{
${ }^{14}$ It is quite possible that these estimates of move rates are a lower bound. The linking algorithm taken from Price et al. (2019) uses place of residence as an input to the machine learning algorithm, and thus will tend to be more successful matching individuals who didn't move residence compared to those who did.
} 
$\Gamma_{s t}$ represents state by year fixed effects. As in Tabellini (2020), changes in the fraction of city residents who are European immigrants who arrived in the last decade is our measure of changes in immigration over time. ${ }^{15}$ We also consider a version of equation (1) estimated in levels, where we additionally include city fixed effects. These local labor market specifications closely align to those used in Ager and Hansen (2017) and Tabellini (2020).

At the local labor market level, our primary outcomes of interest are changes in the labor force participation rate and log changes in the average occupation score, our proxy for income growth. By controlling for state by year fixed effects, our estimates of the effects of immigration compare cities within the same state with differential changes in the fraction of city population who are immigrants. In all local labor market specifications, we cluster standard errors at the MSA level and each city is given equal weight.

In contrast to results obtained from local labor market specifications, we also consider individual specifications, where treatment is assigned on the basis of the labor market in which the individual originally resided. For our results using worker-level data, our baseline specification is given by:

$$
\Delta Y_{\text {iacst }}=\beta_{1} \Delta \text { FracImmig }_{c t}+\Gamma_{s t}+\alpha_{a}+\varepsilon_{\text {iacst }}
$$

where $\Delta Y_{i t}$ represents the change in the labor market outcome $Y$ for person $i$ between $t-10$ and $t$ and $\Delta$ FracImmig $g_{c t}$ represents the change in the fraction of the city population who are recent European immigrants between $t-10$ and $t$ for the city $c$ in which the individual resided in time period $t-10$. At the individual level, we also include age fixed effects, $\alpha_{a}$, to control for changes in labor market outcomes that may naturally vary with an individual worker's life cycle.

At the individual level, we again study changes in labor force participation and income, proxied by the log occupation score of the worker's occupation. However, with our linked data, we also consider the labor market outcomes of moving out of the city, switching occupations, and whether or not there was an occupation switch to a higher or lower paying occupation. Again, controlling for state by year fixed effects, our estimates of the effects of immigration at the individual level compare individuals in different cities within the same state where the two cities faced differential changes in the fraction of city residents who are immigrants. In all

\footnotetext{
${ }^{15}$ Tabellini (2020) also shows, however, that results are robust to considering all immigrants, not just recent ones and not just ones of European origin.
} 
individual specifications, we cluster errors at the MSA level and each person is given equal weight.

The most important distinction between the individual level specification and the local labor market specification is that treatment in the individual specification is assigned to the individual on the basis of the original labor market the person resided in. Thus, the estimates of the impacts of immigration on labor market outcomes in our specifications reflect the impacts for the original residents of the city, including those who moved away and excluding those who moved in. In this way, our individual level specifications are able to account for the selective migration response to changes in immigration. Alternatively, we can re-aggregate our linked data to construct local labor market estimates for the original residents of each city to address selective migration. We consider such results in Section 4 and find them to be similar to our individual level regressions.

In addition to accounting for migration, there are three additional important distinctions between our approach for studying individual labor market outcomes and local labor market outcomes. First, by focusing on individual labor market outcomes, changes in labor force participation and income will in part be driven by natural life cycle patterns. For example, in Figure 1, we show the average labor force participation rate and average occupation score (conditional on working) at each age, averaged across the years 1910-1930. There are large increases in labor force participation and income in early years of life and significant decreases, particularly in labor force participation, for older workers. As a result, if there are differences in the initial age distribution of workers that are correlated with changes in immigration, these life cycle patterns could confound our estimates of the effects of immigration on native labor market outcomes. To account for this, in our worker-level specifications, we control for age fixed effects. However, in Online Appendix C, we also report our baseline individual results where we do not include age fixed effects for comparison. We observe that these results for labor force participation and income are even more different from our findings at the local labor market level than our baseline.

A second important distinction between our individual level and local labor market results is that to study differences in labor market outcomes, we focus only on those individuals who were originally in the labor market in the initial year considered. Given that we restrict the labor market population in the initial year to be between the ages of 15-65, this first of all implies 
that we are excluding young new entrants to the labor market who are aged 15-24 in the second year of the difference, as they were, by construction, outside the labor force in the initial year. We consider in more detail the impacts of immigration on these young workers entering the labor market in Section 5. Because we also include workers ages 56-65 in the original year, this means we additionally are studying the labor market impacts for older workers, aged 66-75 in the later year, who are not present in local labor market estimates. However, we consider the heterogeneous impacts of immigration across age groups, allowing us to see how this could impact our results, and though unreported, if we omit this group, this does not meaningfully impact our average results at the individual level.

Finally, our local labor market specifications place equal weight on each city, whereas our individual results place equal weight on each individual. Thus, our individual level regressions will place greater weight on cities with larger populations. However, in Online Appendix B, we show that when we reweight each individual observation to be one divided by the population of the city they originally resided in, our individual-level results are generally consistent with our primary findings.

\subsection{Instrumental Variables Approach and Identification}

A natural concern with identifying the labor market impacts of immigration off of changes in the fraction of the city population who are immigrants is that immigrants are not randomly assigned to cities, but may selectively choose cities they settle in. If this selection is on the basis of trends in labor market outcomes or other city features correlated with those outcomes, this will bias our estimates of the impacts of immigration. As a result, we follow the identification strategy of Tabellini (2020) and do not directly estimate the specifications in (1) and (2), but use these equations in a two stage least squares setting, where we instrument for changes in the fraction of immigrants in city populations using a shift-share instrument (as in Card (2001)).

Our instrument, taken directly from Tabellini (2020), constructs predicted changes in the share of immigrants in each city using the year 1900 settlement patterns of immigrants by their region of origin and the total in-flows of immigrants from each region from 1910-1930. 
Formally, we construct the predicted change in the share of the population who are immigrants for each city $c$ in each time period $t \in\{1920,1930\}, \Delta$ PredFracImmig ${ }_{c t}$, as:

$$
\Delta \text { PredFracImmig }_{c t}=\frac{1}{\widehat{P}_{c, t}} \sum_{i} \omega_{i, c, 1900} \text { Immig }_{i,-c, t}
$$

where $\hat{P}_{c, t}$ is the predicted population of city $c$ in the time period $t$ (based on average urban growth rates to avoid any direct impact of immigration on city population), $\omega_{i, c, 1900}$ is the fraction of all immigrants of region of origin $i$ who reside in city $c$ in the year 1900, and Immig $_{i,-c, t}$ is the total immigrants in-flows to the United States from region $i$ between time periods $t-10$ and $t$, omitting the inflows that ultimately resided in city $c .{ }^{16}$ Summary statistics for the instrument are visible in Table 1 and additional details of how this instrument is constructed are available in Online Appendix A.

As discussed in Tabellini (2020), the key identifying assumption when using this instrument is that the variation in immigrant settlement patterns in 1900 is unrelated to subsequent changes in labor market outcomes (see also Goldsmith-Pinkham et al. (2018)). Tabellini (2020) shows that this instrument for predicted immigration is uncorrelated with past trends in labor market outcomes from 1900-1910, that results with this instrument are robust to controlling for time trends in certain city characteristics, and that results are robust to controlling for initial city and immigrant populations. As we use the same instrument and start from the same labor market outcomes as in his work, our local labor market results share these robustness characteristics. However, we show explicitly that robustness to these features continues to hold in our individual specifications in Online Appendix B.

We also consider additional sources of variation in immigration across cities, using plausibly exogenous variation in immigration driven by the Immigration Acts of the 1920s and World War I, as in Ager and Hansen (2017), Abramitzky et al. (2019), and Tabellini (2020). Immigration policy between 1910 and 1930 heavily restricted immigrant in-flows from certain European nations, initially due to WWI (restricting in-flows from non-Allied nations), and then later due to the Immigration Acts of 1921 and 1924, which imposed region-specific immigration quotas. As argued in both Abramitzky et al. (2019) and Tabellini (2020), this source of variation

\footnotetext{
${ }^{16}$ By using the predicted population in the denominator for our instrument, our variation will not conflate endogenous changes in the native population associated with immigration with actual changes in immigrant flows, a concern raised in Card and Peri (2016).
} 
substantially reduced the serial correlation in immigrant inflows over time, and thus is unlikely to conflate the short run and long run responses of the economy to immigration, a concern raised in Jaeger et al. (2018). ${ }^{17}$ Our results using these alternate sources of variation are described in more detail in Online Appendix B. We find very similar results as in our baseline.

We note, however, that our results remain of interest even in the case where the identifying assumption is not satisfied. Given that we are starting from the same populations and same instruments for changes in immigration as existing literature, to the extent that we find differences in results observed at the individual and local labor market levels, this suggests that selective migration is important to consider in evaluating the impacts of immigration in this historical context.

A concern specific to our empirical strategy is that if the rate at which we match workers across time is correlated with the treatment, then our estimates of the impacts of immigration may be biased. We show in Online Appendix B that the likelihood of being matched across time is uncorrelated with the increase in the fraction of immigrants in the population of original city of residence. ${ }^{18}$ This mitigates concerns about selective matching that is correlated with the treatment.

\section{Economic Impacts of Immigration for Original Residents}

We begin our analysis of the economic impacts of immigration by considering local labor market outcomes and show that we find comparable results to those in the literature. We then analyze the individual level outcomes for workers, assigning treatment status on the basis of the city the worker was originally in.

\subsection{Average Local Labor Market Level Impacts of Immigration}

We start by verifying that our linked sample of Census records produces comparable results to current work analyzing the impacts of immigration on natives’ economic outcomes over this same time period. We aggregate our final linked individual Census data to the city

\footnotetext{
${ }^{17}$ Prior to using the WWI and quota instrument directly, we find that a correlation across decades in changes in predicted immigration, our original shift-share instrument, of 0.64 . While this correlation is non-negligible, it is on its own sufficiently low to mitigate concerns about conflating short-run and long-run impacts of immigration, as discussed in Jaeger et al. (2019).

${ }^{18}$ We also show that the likelihood of having an occupation that is "not yet classified" is uncorrelated with changes in the fraction of the population who are immigrants.
} 
level and then estimate the impact of the fraction immigrants on workers being in the labor force and the log of their average occupation score, estimating both in levels and in first differences.

Table 3 presents our shift-share IV estimates of these local labor market level impacts. For comparison, we also present in columns (1) and (3) a replication of the results in Tabellini (2020). ${ }^{19}$ Columns (2) and (4) report our results for our final linked sample of individuals, aggregated up to the city level. In our level specifications (columns (1)-(2)), city and state by year fixed effects are included; in our first difference specifications (columns (3)-(4)), state by year fixed effects are included. We do not report the first stage estimates of the impact of our instrument on actual changes in the fraction of immigrants in each city, but show in Online Appendix $\mathrm{C}$ that our instrument strongly predicts changes in immigration in the direction we would expect.

Our point estimates line up nicely with the findings in Tabellini (2020), suggesting our linked sample is representative of the average effects. ${ }^{20}$ We estimate similar impacts of immigration on labor market outcomes, with higher fractions of immigrants and increases in immigration generating increases in labor force participation and incomes. ${ }^{21}$ Our level estimates imply that a five percentage point increase in the fraction of immigrants in a city raises labor force participation by nearly a full percentage point and incomes by roughly $0.5 \% .{ }^{22}$ These findings are also consistent with the findings of Ager and Hansen (2017) and Abramitzky et al. (2019), who look at similar estimates at the county-level.

Before analyzing individual level outcomes, we first consider how these findings at the local labor market level are impacted when we account for the migration patterns in and out of each city. We do this by using our linked data to construct a counterfactual version of each city comprised of all the individuals who originally resided in the city. For example, to analyze changes in employment and income between 1920 and 1930 in Baltimore, MD, we start with the employment and incomes of the original population residing in Baltimore in 1920. We then

\footnotetext{
${ }^{19}$ For this replication, we use the data and code provided in the replication files for his paper, adjusted to match the specifications we consider.

${ }^{20}$ Relative to the original results reported in Tabellini (2020), we omit the two cities, New Bedford, MA and Sacramento, CA for all years in the data; Tabellini (2020) only omits these for the year 1920. This accounts for differences in point estimates in our replication of his work relative to the published version.

${ }^{21}$ While we do not report it, we find that we cannot reject the null hypothesis that our point estimates are the same as those obtained in Tabellini (2020).

${ }^{22}$ We follow Tabellini (2020) and discuss our results for a five percentage point change in the fraction of immigrants, as this is roughly the average change in this fraction between 1910 and 1920; see Table 1.
} 
construct a counterfactual Baltimore for the year 1930, comprised of only those individuals residing in Baltimore in 1920, including those who moved out between 1920-1930 and omitting those who moved in over that same time period. In this way, we account for any possible migration response to changes in the fraction of immigrants in the local labor market. Because we focus on changes in the population in each city, we only present results in first differences and not in levels.

Table 4 presents the results of this counterfactual exercise focusing solely on the original residents of the local labor market. We continue to find that there is a significant positive effect of immigration on labor force participation for these original natives. However, when we focus purely on the original residents of each city, we find that no statistically significant impact on incomes as a result of changes in immigration. Further, given the size of our standard errors, we cannot rule out large negative effects on income. We observe that the magnitude of our negative point estimate for immigration is comparable in absolute value to the statistically significant positive effect obtained in Table 3 and the differences in these two coefficients are statistically significantly. Thus, before even considering individual-level regressions, these findings suggest that local labor market estimates of the impacts of immigration, such as those in Table 3, may be misleading.

\subsection{Average Worker-Level Impacts of Immigration}

To understand better the migration response to changes in immigration, as well as which types of workers are impacted by changes in immigration, we now consider results estimated at the individual level. To focus on the original residents of a given labor market, similar to our above counterfactual construction of local labor markets, we estimate differences in labor market outcomes at the individual level, assigning the treatment of changes in the fraction of immigrants on the basis of the city there individual lived in in the initial period. For all our estimates, we restrict attention to males in who were between the ages 15-65 in the first decade they are observed that can be linked across two Census waves and who were residing in one of the 178 cities we study in the initial period. We again include state by year fixed effects in all specifications and cluster standard errors at the MSA level.

Table 5 presents our results at the worker level, reporting results for whether or not workers moved out (column 1), changes in labor force participation (column 2), log differences 
in occupation scores (conditional on being initially in the labor force) (column 5), and whether or not the worker switched (one-digit) occupations (conditional on being initially in the labor force) (column 5). ${ }^{23}$ Because labor force participation changes can occur through either entering or exiting the labor force, we also report labor force entry and exit outcomes separately (columns 3 and 4). ${ }^{24}$ Further, because our measures of income are defined at the occupation level, changes in income must come through changing occupations. As a result, we also report results for whether or not there was an upward or a downward occupational switch (i.e. an increase or decrease in log occupation scores, measured at the three digit level) (columns 7 and 8).

At the individual level, we find that increases in immigration lead to increases in labor force participation, and of roughly the same magnitude as observed as the local labor market level. This comes both through increased entry to the labor force, as well as a decrease in exit from the labor force. However, in contrast to the local labor market findings in Table 3, we find no impact of immigration on incomes, though we cannot rule out moderately negative effects. A key reason for the difference in these outcomes is that increases in immigration led to increased out-migration by the original residents of the city. Our estimates imply that a five percentage point increase in the fraction of immigrants increasing the probability of moving out by 2.85 percentage points or by $9.5 \%$. This selective migration response is key to understanding the economic impacts of immigration on natives and something we explore further in analyzing which types of workers are moving out in response to increased immigration.

Notably, we find that workers in areas with increased numbers of immigrants were less likely to change occupations. A five percentage point increase in the fraction of immigrants in the city reduces occupational switching by 1.5 percentage points, or $3 \%{ }^{25}$ The economic interpretation of this finding is, on its own, ambiguous. Lower occupational switching could represent more stability in the local labor market and be a positive outcome, especially if it

\footnotetext{
${ }^{23}$ Though unreported, we find that if we use the inverse hyperbolic sine transformation instead of logs to compute income growth, and include those initially outside the labor force, our results are very similar to those reported here.

${ }^{24}$ These outcomes are defined as the incidence of making a transition from out of the labor force to in the labor force (entry) or the incidence of making a transition from in the labor force to out of the labor force (exit). As these outcomes can be potentially influenced by the initial distribution of workers across labor force states, we report results in Online Appendix C where we interact changes in the fraction of immigrants with workers' initial labor force status.

${ }^{25}$ The baseline rate of occupational switching of $50 \%$ at the one digit level over a ten year span may seem high. There is likely a nontrivial amount of spurious occupational switching in the data due to how interviewers coded worker responses and how these were mapped to occupations; this problem persists even in current labor market data (see, for example, vom Lehn et al. (2019)).
} 
means that natives are less likely to make a downward occupational switch. On the other hand, reduced switching could mean that workers have a hard time making career advancements, and get stuck in their current occupations, unable to advance to higher-paying work. Looking at the probability of making an upward or downward switch, we see that increased immigration has no significant impact on upward occupational switching. However, increases in immigration substantially reduce the probability of making a downward occupational switch. We interpret this findings as suggesting that increased immigration may provide some labor market insurance for natives, reducing the incidence of negative labor market shocks which would cause a career regression.

Prima facie, it may seem hard to square the fact that increased immigration has no impact on occupation scores with the finding that workers are both less likely to make a downward occupational switch and no less likely to make an upward occupational switch. To reconcile these findings, in Table 6, we present results for the probability of observing a log occupation score change of different amounts, breaking income changes into increments of 0.25 , or $25 \log$ points. This allows us to trace out the distribution of income changes through occupational switching and how that changes in response to increased immigration.

We observe in Table 6 that workers are indeed more likely to observe no occupational income score change as a result of immigration, remaining in their current occupation. Considering the probability of making a downward occupational switch, we see that the likelihood of making a switch to an occupation that pays up to 25 log points less than the current occupation is substantially reduced, and that there is also a reduction in slightly larger decreases, between 50 and 75 log points. This is the key source of the insurance effect we have observed. However, we also observe that the probability of switching occupations and losing 75 log points or more of one's current income increases when there are increases in immigration, albeit by a smaller amount than the reductions in the likelihood of making a smaller downward occupational switch. ${ }^{26}$ Thus, although the overall incidence of downward occupational switching is reduced, conditional on making a downward switch, the risk of large income losses has increased. This reconciles the lack of any average income change with the increased insurance against small

\footnotetext{
${ }^{26}$ We note that these losses are still conditional on participation in the labor force, and not losses due to leaving one's job entirely. These type of large career regressions are low probability events on average, occurring to only $3 \%$ of workers. We also note that since we measure median income of the occupation, a sizable portion of these losses may come by moving to occupations where a larger fraction of workers are not working full-time hours.
} 
amounts of labor market risk. We interpret these findings as implying that while increases in immigration provide some insurance against small labor market shocks, they are unable to fully mitigate larger labor market risk associated with a large displacement from one's occupation.

For upward occupational switching, we observe that for most types of upward switches, the probability of moving up the career ladder is unaffected by changes in immigration. For upward switches raising income between 50-75 log points, there is some reduction, however, with increases in immigration. But overall for the average worker, movements up the career ladder through upward occupational switching are largely unaffected by increased immigration. Thus, we find no evidence that increases immigration impede occupational upskilling, but no evidence that they generate it either.

\subsection{Variation in Worker-Level Impacts by Age}

To summarize, we find on average that increased immigration leads to higher labor force participation for natives and no impact on average incomes, but increased outmigration and decreased occupational switching, primarily a decrease in downward occupational switching. We now turn to the question of who are the workers experiencing these changes and explore heterogeneity in worker level responses to changes in immigration. That is, we are interested in now understanding who are the "winners" and the "losers" of increased immigration.

We first consider how the impact of immigration varies across workers of different ages. Table 7 shows our findings where we interact the treatment of changes in the fraction of immigrants with being in different 10 year age bins (15-24, 25-34, 35-44, 45-54,55-65), defined by the worker's age in the initial year he is observed. We report the interaction term for each age group, omitting a direct effect instead of a reference age group. Thus, our results can be interpreted as the average effect for workers in each age group. We again consider the same set of labor market outcomes as in Table 5.

In general, we find substantial heterogeneity in the impacts of immigration across workers of different ages for many of our labor market outcomes. For example, there is a strong age gradient in the out-migration response to increased immigration, with workers under the age of 35 much more likely to move out and older workers, especially those over the age of 55, much more likely to stay. As seen in Table 2, young workers are already more likely to move out in general, however, the age gradient in our estimated results is much steeper than in average 
migration rates. For example, a five percentage point increase in the fraction of immigrants generates a nearly five percentage point increase in the likelihood of moving for 15-24 year olds, or a nearly $15 \%$ increase in the likelihood of moving out (using the Table 2 data as a baseline). However, the rate at which workers age 45-54 move out increases by roughly 1.3 percentage points, or a $5 \%$ increase in moving out, with a five percentage point increase in immigration. For workers over the age of 55, our point estimates, though noisy, imply no out-migration in response to increased immigration, even though on average, nearly $30 \%$ of these workers move out of their original city of residence.

We also observe that gains in labor force participation are also concentrated among young workers. As seen in column (2), workers ages 15-24 are the only workers to experience an increase in labor force participation as a result of increased immigration. Prime-aged workers see no significant change in labor force participation due to immigration, and old workers see large reductions in labor force participation as a result of increases in immigration. The increase in labor force participation for young workers is largely accomplished through increased entry to the labor market. Given the high rates of labor force participation for men over this time period (see Figure 1 and Table 1), we interpret this large increase as immigration accelerating labor force entry for younger workers and not increasing labor force participation from workers who would otherwise not participate.

In contrast to the results for labor force entry, we see that for workers under age 55, there was a relatively symmetric impact of immigration on labor force exit across age groups, with these workers slightly less likely to exit the labor force as a result of increased immigration. The exception here is workers over the age of 55, who saw a much higher likelihood of exiting the labor force as a result of increased immigration. This substantial increase in exiting the labor force, coupled with the substantial reduction in labor entry is what accounts for the substantial reduction in labor force participation for older workers with increased immigration.

It is not obvious how to interpret these results in terms of welfare for younger or older workers. It may be that increased labor market entry by young workers is because the returns to work have risen substantially, raising the opportunity cost of non-employment, or it may be driven by economic necessity in their households. ${ }^{27}$ Similarly, it may be that older workers

\footnotetext{
${ }^{27}$ In Table C.15 of Online Appendix C, we consider how labor force participation changes differed based on initial labor force status. We see that the increase in labor force participation is primarily concentrated among workers
} 
exiting the labor force represents an ability to retire early and is a positive sign for welfare or it may be that older workers experience a displacement effect and involuntarily exit the labor force. Regardless of the interpretation, the key finding we emphasize is that the labor force participation changes induced by increased immigration are concentrated on the young and the old and increases in labor force participation are observed solely for young workers and not for prime-age nonparticipants.

We also observe significant differences in how incomes were impacted by immigration across age groups. Younger workers experienced modest income losses as a result of increased immigration, whereas older workers saw no significant impact, though for the oldest workers, we cannot rule out meaningful income gains. This heterogeneity in income changes is driven by heterogeneity in occupational switching patterns. Workers of all ages experience some form of the insurance effect, with the likelihood of making a downward occupational switch decreased with increased immigration. However, workers under the age of 25 also see an equivalently sized decrease in the likelihood of making an upward occupational switch, whereas older workers do not. Similar to our results in Table 6, we examine age heterogeneity in how the distribution of income/occupation changes responds to increased immigration in Online Appendix C, and find results very similar to those seen in Table 6, with the age gradients we find in Table 7.

Given these findings, in spite of some ambiguity of how to interpret our findings for labor force participation, we argue that young workers are losers from increased immigration - they move away at a higher rate, see modest income losses, and are less likely to make career advancements. In contrast, older workers seem to fare better, as they are less likely to move, and may experience some income gains.

\subsection{Variation in Worker-Level Impacts by Worker Skill}

who were not initially in the labor force and not in school. While there is an effect for workers initially in school, it is much smaller. In Tables C.12 and C.13, we also observe that there is no significant average labor force effect for workers whose parents were both U.S. natives, driven by a much lower labor force response by the young. Overall, since the fraction of workers in not in school and not in the labor force are primarily young workers (74 percent are under the age of 25) and measured labor force participation rates are so high for prime-aged workers (nearly 95\%, as seen in Figure 1), we interpret this increase in labor force participation as primarily accelerating entry for younger workers who were not originally in school. 
Immigration may also have heterogeneous impacts across worker skill levels. In our data, we do not directly observe education and so we are unable to use education as a measure of skill. Instead, we proxy for skill by looking at how outcomes vary based on a worker's initial one-digit occupation, where we rank occupations by their average occupation score to denote the level of skill (reported in Online Appendix A). Again, we control for age fixed effects in these specifications, so we account for the fact that older workers are more likely to be in certain occupations as part of their life cycle career progression. We also control for one-digit occupation, so the effects of increased of immigration for workers in each occupation are estimated relative to other non-exposed workers in that same occupation.

In Table 8, we present results of the impacts of increased immigration for workers of different skill levels, separately estimating outcomes for workers based on their initial one digit occupation (or non-participation in the labor market). We list one-digit occupations in ascending order of average occupation score, with labor market nonparticipants first, followed by farmers/farm laborers, which has the lowest average occupation score, all the way up to professional/technical occupations, which has the highest average occupation score. As before, we do not omit any of the one digit occupations in this specification and so the coefficient for each interacted independent variable represents the total effect for workers in that skill group.

We observe significant differences in the impacts of immigration on individual workers based on their initial level of skill. Workers who are low skilled are much more likely to move out in response to immigration, whereas high skilled workers are more likely to remain in the original labor market. These effects are quite large, with the increased out-migration effect for the lowest skilled workers in laborer work, either in farm work or more generally, implying that for every percentage point increase in the fraction immigrants in a city, these workers' outmigration rate increases by a percentage point or more. Further, this out-migration response is roughly five times larger than for high skilled workers in managerial or professional occupations.

We also find that low skilled workers are much more likely to see a decline in their occupational incomes, in particular, farmers and farm laborers, whereas higher-skilled workers see an increase in their incomes. Again, these effects are large. A five percentage point increase in the fraction of immigrants in the city is estimated to reduce incomes of laborers and farm laborers by $5-10 \%$. These income losses are largely driven by a substantially decreased likelihood of making an upward occupational switch, though for non-farm laborers, there is also 
an increased likelihood of making a downward occupation switch. In contrast, higher-skilled workers' likelihood of making an upward occupational switch increases in response to immigration. In Online Appendix C, we present results for changes in different parts of the distribution of occupation switches for workers differentiated by initial occupation. We observe that lower skilled workers, while still receiving some insurance against small declines in occupational income, also faced increased risk of larger income declines than higher skilled workers. The overall implication of this is that low skill workers face much worse labor market outcomes than high skill workers in response to immigration.

Notably, we observe little skill heterogeneity in labor force participation, with most workers experiencing a small, if any, increase in the likelihood of participating in the labor force. Since having an occupation requires workers to already be in the labor force in the initial period, this estimate purely represents reduced labor market exit for these workers. The largest increase in labor force participation is observed for workers originally outside the labor force; as previously shown in Table 7, this is exclusively driven by young non-participants.

In summary, we see that low skill workers are clear "losers” of increased immigration, as they are more likely to move out and experience income losses. In contrast, higher skilled workers are clear “winners” of increased immigration, as they are less likely to move and more likely to see income increases. Thus, among this population of the original natives residing in a city, increased immigration exacerbates income inequality.

\subsection{Outcomes for Movers vs. Stayers and Evidence of Displacement}

We conclude our analysis of the impacts of immigration on the natives originally residing in local labor markets by examining evidence on how the effects of immigration vary for movers and stayers. Because native out-migration is an outcome of changes in immigration, and is an endogenous choice made by individuals, we cannot interpret differences in outcomes between movers and stayers as causal. However, given what we observe for these differences, we present a few pieces of supporting evidence for a causal story that workers who leave the local labor market due to immigration are experiencing some form of displacement. Table 9 shows our results split out by movers and stayers, while controlling for the average effects for movers.

When we look at how moving interacts with increases in immigration, we observe that the outcomes for movers are significantly different than both other movers and workers who 
stay. On the one hand, workers moving away from areas experiencing increased immigration are more likely to be in the labor force 10 years later than either stayers or the average mover. However, these workers see larger income losses than stayers or movers from cities not experiencing immigration increases. A mover from a city where there is no change in the immigration sees a $11 \%$ reduction in incomes with the move, largely because the probability of making a downward switch is higher than stayers (though the probability of an upward switch is slightly higher as well). However, if a worker moves away from a city experiencing a five percentage point increase in the fraction of immigrants in their original city, their income falls by an additional $1.7 \%$. This is because workers moving away from cities with increases in immigration are much less likely to make an upward occupational switch. They also show no signs of receiving insurance against downward occupational switches. This is consistent with the idea that the insurance provided by increased immigration operates through the local labor market, as in Cadena and Kovak (2016), and thus workers who move away lose this benefit.

In contrast, the effects of increased immigration for those workers who choose to stay in their original city of residence are largely positive. There are also increased effects on labor force participation, but also a moderate increase in earnings, on par with the average increase observed in our local labor market analyses in Table 3. This comes from the insurance effect of a reduced likelihood of making a downward occupational switch, and though unreported, conditional on a downward switch, we observe no increase in larger switches and losses for these workers.

With the available data we have, we cannot directly assess the causal motives for why some workers move out of a city when there is increased immigration and some don't. However, we argue that our findings of different outcomes for movers and stayers, though not causal, is supportive of a displacement effect for workers who end up leaving the local labor market. We see some evidence of this in Figure 2, where we plot the coefficient on the out-migration effect from Table 8 for each one digit occupation opposite the national fraction of immigrants observed in 1920 or 1930 who arrived in the last ten years and who are working in that occupation. We observe a substantial positive correlation between the jobs in which immigrants work in and the jobs whose workers move out of the cities they originally resided in. ${ }^{28}$ This is supportive of the

\footnotetext{
${ }^{28}$ While the positive correlation is quite strong, we do note a couple of outliers that move in a different direction in farmers/farm laborers and craftsmen, as migration rates for farmers (craftsmen) is higher (lower) than we would
} 
idea that immigrants enter cities and seek work in certain occupations, increasing the local labor supply and driving away natives because of either lower wages or higher non-employment for workers specializing in those jobs. With this perspective, we would consider that these displaced workers who move away from their original labor market as "losers" of immigration, whereas those who stay are "winners."

We further note that these estimated losses for workers who move out of these areas may well be a lower bound for the losses experienced by workers exposed to immigrant competition. Workers who move in response to economic shocks may be positively selected on the gains they receive from moving (Borjas et al. (1992), Dahl (2002)) and thus these workers moving away from cities may fare much better than workers who face greater barriers to geographic mobility. For example, in Online Appendix C, we show that for black workers, who may have faced greater barriers to mobility, increased immigration lowered labor force participation, lowered earnings, lowered the likelihood of making an upward occupational switch and provided no insurance against downward occupational switches. Thus, those who lost from immigrant competition and were unable to move in response to that shock may have fared worse than what we observe for movers.

An alternative explanation to displacement from immigrant competition is that some workers have preferences over living in cities with fewer immigrants (for example, due to prejudice), and are willing to experience worse outcomes to avoid living in a city with more immigrants. To assess this alternative story, we consider where workers move to, and whether or not these locations have lower levels of immigrants. If workers are leaving to avoid immigrant populations, we would expect that they would migrate to cities where there are fewer immigrants.

We consider this possibility in Table 10, where we consider the outcomes of moving out to a location whose fraction of recent immigrants in the population is in the first, second, third or fourth quartile. For workers who move to one of the cities in our sample, we use the observed

predict from other occupations. An important limitation of this simple correlation and the interpretation we apply is that we presumes that workers in the same one digit occupation are equally substitutable, which would generate a displacement effect. For these two occupations, we note that among farm laborers (which are most of these workers, since we have an urban sample), the substitutability of native and immigrant labor is likely high, whereas the degree of substitutability of craftsmen between native and immigrant labor is likely much lower. Further study of the substitutability of workers within these occupations would be needed to obtain a more precise estimate of a displacement effect. 
fraction of immigrants for that city; for workers who move to smaller city or more rural area, we use the state fraction of immigrants net of the cities in our sample. We observe no evidence that move-out rates to low immigrant cities, in the first or second quartile, increased in response to increased immigration. Instead, native migration flows primarily increase to cities whose fraction immigrants is in the $3^{\text {rd }}$ quartile. Thus, we do not see strong evidence of out-migrants avoiding immigrants in their decisions of where to move to. ${ }^{29}$

\subsection{Relation to Abramitzky et al. (2019)}

At first glance, our findings that changes in immigration have no impact on native worker log occupation scores appears to differ from the recent findings of Abramitzky et al. (2019), who show that declines in immigration associated with increased immigration quotas in the 1920s are also associated with declines in income (also measured by occupation scores) for native workers. They identify this as a "puzzle," given that we might expect a reduction in local labor supply should raise earnings for native workers. Abramitzky et al. (2019) also show in their Table 1 that these results persist for a sample of linked male workers between the ages of 16-55, both for movers and stayers, even when restricting to urban areas.

However, our results are consistent with their findings once we account for two key differences between our approaches. First, in the linked sample used in Abramitzky et al. (2019), the immigration treatment is assigned based on the latter year of the two years over which differences are taken. As a result, the effects on income are estimated for the original population that stayed and the new move-ins to the region, excluding the workers who move away from the area. As we have shown in Table 9, these workers who moved away from areas with increased immigration experience wage losses, and thus their exclusion from the results in Abramitzky et al. (2019) raises the estimated impact of immigration on natives. Second, when separately considering the effects for movers and stayers, Abramitzky et al. (2019) constructs the local labor market total of all recent stayers or new move-ins and looks at the level of their incomes. This construction implicitly mixes the changes in income associated with changes in immigration as well as changes in selection in terms of who moved in and who stayed. Our

\footnotetext{
${ }^{29}$ One potential concern is that if natives are not moving to areas without lower levels of immigration, they may not be moving to avoid immigrant competition in the first place. However, we note that the evidence in Table 9 suggests that movers were more likely to switch occupations than stayers, and thus they may have switched into jobs exposed to different levels of immigrant competition than they faced in their original job.
} 
findings for stayers (Table 9) are consistent with their findings, as our estimates show that stayers experience income gains from increased immigration. In the following section, we consider who the new move-ins are and what happens to them. While we find income gains for these new native move-ins, we also observe that increased immigration worsens the selection of these new move-ins. Thus, the findings of Abramitzky et al. (2019) that new move-ins have lower incomes when there are increases in immigration can be accounted for by the worsening selection of these move-ins, documented in the following section. ${ }^{30}$

As a result, we argue that our findings are consistent with the findings of Abramitzky et al. (2019) that immigration declines generate declines in the income of workers who are ultimately in the local labor markets where immigration slowed down. However, given our findings on the effects of out-migration for natives originally in treated cities, we would argue that the puzzle described in Abramitzky et al. (2019) is further complicated because it misses an important subset of workers displaced by immigration, for whom reductions in immigration associated with U.S. immigration policy changes would have resulted in better labor market outcomes.

\subsection{Additional Outcomes and Robustness Exercises}

We present a variety of additional results in Online Appendices B and C. In Online Appendix C, we present additional results showing the impacts of changes in immigration on family formation outcomes - the probability of individuals being married, single, widowed, or divorced. Consistent with the results in Carlana and Tabellini (2020), we find that local labor market analysis finds that increased immigration is associated with more marriages, but we show that this effect disappears for linked individuals in our sample. This difference in results is not driven by selective migration, but by the fact that the only impact on marriage is observed for

\footnotetext{
${ }^{30}$ Another notable difference between our empirical strategy and that of Abramitzky et al. (2019) is that their exercises are implemented in a difference-in-differences framework using measures of immigration quotas directly and location fixed effects. They also utilize data from the year 1900. To implement the equivalent of their specification in our shift-share approach at the individual level would require a consistent panel of individuals from 1900 to 1930, and have a very different interpretation, assessing the 20-30 year impact of immigration on an individual worker. As a result, we do not pursue this specification. Alternatively, we could add in individual linked data from 1900-1910 as an additional observation in our specification. However, interpreting our results for these workers is also more complicated, as changes in immigration in-flows from 1900-1910 do not have a plausibly exogenous interpretation, as they are not impacted by WWI or the immigration quotas. However, in Online Appendix B, we do use data from 1900 to 1910 to construct city-level pre-trends for the individual residents of each city at each age. We find that our results are robust to controlling for these age-city pre-trends.
} 
workers originally under the age of 15 . Increases in immigration lead these young workers to be more likely to be married 10 years later, and have no impact on workers originally 15 or older when first observed.

Our results thus far have exclusively focused on labor market outcomes for men, largely because labor force participation rates for women were low in this time period and the inherent difficulties in linking women across multiple Census waves. However, we are able to link a significant number of women in our sample and we report our estimates of the impacts of immigration on them in Online Appendix C. We find broadly similar results to the average results for men in Table 5.

We also present in Online Appendix C how the impacts of immigration vary for workers who are second generation immigrants (children of immigrants) versus children with U.S. born parents and how the impacts of immigration vary by race. We find that our results are not particularly dependent on workers' parentage with the exception of changes in labor force participation. We only find significant average effects on labor force participation changes for workers who had at least one parent who was an immigrant; there is no average effect for workers whose parents are U.S. born. This difference is driven by a substantially lower impact on labor force participation changes for young workers whose parents are U.S. born. In terms of differences across race, we find that the average effect for white workers is very similar to our baseline findings, which is perhaps unsurprising given less than $10 \%$ of our linked sample is non-white. As noted before, we find significant negative impacts for black workers, consistent with similar findings in Ager and Hansen (2017). As a result, we would argue that black men are also some of the "losers" from increased immigration over this time period.

Finally, in Online Appendix C, we also report our findings when we use simple OLS instead of our IV strategy for obtaining variation in changes in immigration. We find that these results look very similar to our baseline results along most dimensions. The most significant difference is that our estimates of out-migration by natives become statistically insignificant (and even negative). This is not surprising, however, given that immigrants likely select their location of residence on local labor market characteristics that are likely appealing to natives as well, which would reduce the average out-migration response for workers in these labor markets.

We report several robustness checks in Online Appendix B. We show that our results are robust to using an alternative identification strategy, using variation in predicted immigration 
based on WWI and U.S. Immigration Policy in the 1920s as our instrument for the fraction immigrants in each city. Our results are also robust to including not yet classified occupation observations with imputation and reweighting individuals to be consistent with local labor market specifications generate consistent findings. We also show that our results hold when including allowing for possible differential trends in city characteristics (for example, fraction black, skill composition, manufacturing value added level, city size), as in Tabellini (2020). Finally, we use data from 1900-1910 to construct age-specific pre-trends for changes in individual outcomes for those workers who originally reside in each city (including those workers who move away). We construct these pre-trends for each city and each age, and then control for these in our baseline specification. We find that our results are largely unchanged when these pre-trends are included as controls.

\section{Economic Impacts of Immigration for New Entrants: Young and New} Arrivals

As a final piece of insight, we consider how increased immigration impacted individuals who were new entrants to labor markets. These new entrants are of two types - a new cohort of workers who originally resided in the city, but were under the age of 15 , and new move-ins to the area.

\subsection{Impacts on New Worker Cohort}

Table 11 reports the labor market outcomes for the men who were originally ages 5-14 in the first year they can be observed, and thus potentially entered the labor market 10 years later when observed again. Since these men were not originally in the labor force, we do not report results in differences, but focus on whether they were likely to move away, participate in the labor force the ten years later and the level of their log occupation score when they do enter the labor market.

We observe that these young men were more likely to move away from the cities they originally resided in, with an effect comparable to the average effect for all workers shown in Table 5. This is not surprising, as it is likely that most of these young men moved with family units captured in the original sample. However, we do note that these young men were much less likely to enter the labor force than other young men. This stands in contrast to the effects on 
labor force participation for the previous cohort of young workers, who were much more likely to enter the labor force earlier as a result of increased immigration. Again, though we cannot interpret the welfare impacts of this effect on labor force participation, we note that there are potentially important dynamic differences in how immigration impacts young workers of different cohorts in the same city. Conditional on entering the labor force, however, the incomes of new young workers in areas with higher immigration are not statistically significantly different from the incomes of other young workers, though we cannot rule out potential large negative differences.

\subsection{Effects of Immigration for New Move-Ins}

Finally, we consider how immigration impacted workers who did not originally reside in treated cities, but who ultimately moved there. To do this, we revisit our results from Table 9, which split out the impacts on immigration on move-outs and stayers, assigning treatment on the basis of the original city of residence. In contrast, in Table 12, we consider the impacts of increased immigration on move-ins and stayers, where treatment has been assigned on the basis of the terminal city of residence, studying the population residing in each city at the end of the decade. We again note that these results cannot be given a causal interpretation, since the migration decision is an endogenous choice in response to changes in immigration. However, these results provide descriptive evidence of what is happening to the workers who move in to cities observing increases in immigration.

The first thing we observe is that there is a large move-in effect (column 1) in response to increased immigration, significantly larger than the move-out effect for the original population. ${ }^{31}$ When we consider separately the outcomes of movers and stayers, we see results for stayers that look very similar to Table 9 - increased labor force participation, increased incomes and a significant insurance effect. ${ }^{32}$ For move-ins, however, while we do not detect a statistically significant impact on changes in labor force participation, we do observe large income gains.

\footnotetext{
${ }^{31}$ We find evidence of US born men moving both between cities in the sample and from other areas not in our sample. Unlike the full sample of in-migrants, in-migrants who originally lived in one of our sample cities are positively selected on both labor force participation and occupation scores.

${ }^{32}$ There are few notable differences, however. The magnitudes of these effects are slightly smaller, and there is now a significant reduction in the probability of moving up the career ladder. Given that we have assigned treatment differently and are studying a substantially different population, it is not surprising that there are some differences with our original findings.
} 
These are realized by a larger probability of moving up to a higher-paying occupation and a much lower probability of moving to a lower paying occupation. Again, since migration is a selective decision, we cannot attach a causal interpretation to these findings. However, we do note that these benefits observed by new move-ins are substantially larger than benefits observed for move-ins to cities with smaller increases in immigration.

This combination of wage gains for new move-ins and for workers originally residing in the labor force can explain why at the local labor market level, we observe overall income gains from increases in immigration. Workers who remained in the labor market and workers who were drawn to the labor market both observed income gains, whereas those workers who left these cities observed income losses. On the other hand, the workers who left their original local labor markets saw income losses, and when they are included, the income gains go away.

An alternative story to reconcile the differences in our results for income at the local labor market level and the individual level is that new move-ins are positively selected from the population as a whole, and thus a change in worker composition induced by immigration raised incomes on average. We show in Online Appendix C, however, that on average, new move-ins are younger and have lower initial occupation scores than move outs and the average worker in this time period (comparing to Table 1). Thus, positive selection was not occurring on average with move-ins.

However, increases in immigration could have changed selection of move-ins and so we consider how move-ins and move-outs from cities experiencing increased immigration compared to other move-ins or move-outs in Table 13. We consider among the population of either moveins or move-outs how changes in immigration relate to the pre-characteristics of these movers, characteristics such as labor force participation, log occupation score, race, and marital status. For move-outs from cities with larger increases in the fraction of immigrants, they were less likely to be initially in the labor force, likely to have lower incomes, more likely to be white and more likely to be married. The selection on move-ins is very similar, albeit with larger magnitudes on the income and racial selection, and a positive selection on initial labor force participation. We do note, however, that the negative selection on income largely goes away for both move-ins and move-outs if we exclude farm workers (column 3), and thus a key part of the selection operates on workers employed in the farm sector. 
Given the generally negative selection of move-ins, particularly on income, we argue that changes in worker composition over initial characteristics did not result in increases in average incomes in cities with increased immigration. If anything, these compositional changes may have reduced incomes. As a result, the cause for our differences in income results at the local labor market and individual level are largely attributable to the selective migration effect.

\section{Conclusion}

In this paper, we have studied the impact of immigration on the labor market outcomes of natives over the years 1910-1930, when immigration flows to the United States were high and exhibited substantial variability due to changes in global conditions and domestic policy. Consistent with existing literature, we find that, at the local labor market level 10 years apart, increases in immigration generate increased labor force participation and increased earnings for native workers. However, using linked data, we are able to show that the local labor market results do not fully reflect the impact changes in immigration have on individuals' outcomes. Once we focus on workers originally residing in the labor market, we find that the increases in labor force participation are solely concentrated among young workers entering the labor market sooner than other young workers and that the income gains are non-existent, implying that aggregate gains are driven by selective out-migration. However, we do show that increased immigration does generate an "insurance effect," as workers are on average less likely to make a downward occupation switch when there is increased immigration.

With our linked data on individual workers, we are further able to identify the relative "winners" and "losers" of immigration. Younger and lower-skilled workers are "losers" from increases in immigration, experiencing income losses and higher rates of out-migration. In particular, those workers who move away from labor market experiencing increases in immigration appear to fare much worse than those who stay, making them "losers" from increased immigration as well. We argue that this represents a form of displacement, as workers' migration responses by skill level are closely correlated with the occupational distribution of immigrant labor entering the U.S. over this time period. In contrast, older and higher skilled workers are "winners" from increased immigration.

Our findings also highlight the importance of understanding the distributional consequences of increased immigration, and may provide some rationale for the puzzle identified 
by Tabellini (2020), that although there are, on average, economic benefits at the local labor market level from increased immigration, there is yet substantial political opposition to immigration. Economic losses by displaced workers may rationalize some native opposition to immigration. Further, given that a significant portion of the economic benefits to native who stay is achieved through reducing the incidence of negative shocks, it is possible that even those natives who benefit from immigration may not appreciate the economic benefits they accrue from immigration. As a result, while there are economic gains on average to increased immigration, these gains may not be sufficient to temper other native motives for opposition to immigration.

\section{References}

Abramitzky, R., Ager, P., Boustan, L. P., Cohen, E., \& Hansen, C. W. (2019). The Effects of Immigration on the Economy: Lessons from the 1920s Border Closure (No. w26536). National Bureau of Economic Research.

Abramitzky, R., Boustan, L. P., \& Eriksson, K. (2014). A nation of immigrants: Assimilation and economic outcomes in the age of mass migration. Journal of Political Economy, 122(3), 467506.

Ager, P., \& Hansen, C. W. (2017). Closing Heaven's Door: Evidence from the 1920s US Immigration Quota Acts. Working Paper.

Borjas, G. J. (1999). The economic analysis of immigration. In Handbook of labor economics (Vol. 3, pp. 1697-1760). Elsevier

Borjas, G. J. (2006). Native internal migration and the labor market impact of immigration. Journal of Human resources, 41(2), 221-258.

Borjas, G. J., Bronars, S. G., \& Trejo, S. J. (1992). Self-selection and internal migration in the United States. Journal of urban Economics, 32(2), 159-185.

Borjas, G. J., Freeman, R. B., \& Katz, L. F. (1996). Searching for the effect of immigration on the labor market. The American Economic Review, 86(2), 246.

Borjas, G. J., Freeman, R. B., Katz, L. F., DiNardo, J., \& Abowd, J. M. (1997). How much do immigration and trade affect labor market outcomes?. Brookings papers on economic activity, 1997(1), 1-90.

Boustan, L. P., Fishback, P. V., \& Kantor, S. (2010). The effect of internal migration on local labor markets: American cities during the Great Depression. Journal of Labor Economics, 28(4), 719-746. 
Cadena, B. C., \& Kovak, B. K. (2016). Immigrants equilibrate local labor markets: Evidence from the Great Recession. American Economic Journal: Applied Economics, 8(1), 257-90.

Card, D. (2001). Immigrant inflows, native outflows, and the local labor market impacts of higher immigration. Journal of Labor Economics, 19(1), 22-64.

Card, D. (2005). Is the new immigration really so bad?. The Economic Journal, 115(507), F300F323.

Card, D. (2009). Immigration and inequality. American Economic Review, 99(2), 1-21.

Card, D., \& DiNardo, J. (2000). Do immigrant inflows lead to native outflows?. American Economic Review, 90(2), 360-367.

Card, D., \& Peri, G. (2016). Immigration economics by George J. Borjas: a review essay. Journal of Economic Literature, 54(4), 1333-49.

Carlana, M., \& Tabellini, M. (2018). Happily Ever After: Immigration, Natives’ Marriage, and Fertility. Working Paper.

Cattaneo, C., Fiorio, C. V., \& Peri, G. (2015). What Happens to the Careers of European Workers When Immigrants “Take Their Jobs”?. Journal of Human Resources, 50(3), 655-693.

Dahl, G. B. (2002). Mobility and the return to education: Testing a Roy model with multiple markets. Econometrica, 70(6), 2367-2420.

Dustmann, C., Schönberg, U., \& Stuhler, J. (2016). The impact of immigration: Why do studies reach such different results?. Journal of Economic Perspectives, 30(4), 31-56.

Foged, M., \& Peri, G. (2016). Immigrants' effect on native workers: New analysis on longitudinal data. American Economic Journal: Applied Economics, 8(2), 1-34.

Goldsmith-Pinkham, P., Sorkin, I., \& Swift, H. (2018). Bartik instruments: What, when, why, and how (No. w24408). National Bureau of Economic Research.

Jaeger, D. A., Ruist, J., \& Stuhler, J. (2018). Shift-share instruments and the impact of immigration (No. w24285). National Bureau of Economic Research.

Kerr, S. P., \& Kerr, W. R. (2011). Economic impacts of immigration: A survey (No. w16736). National Bureau of Economic Research.

Lee, J., Peri, G., \& Yasenov, V. (2019). The Labor Market Effects of Mexican Repatriations: Longitudinal Evidence from the 1930s (No. w26399). National Bureau of Economic Research. 
Lewis, E., \& Peri, G. (2015). Immigration and the Economy of Cities and Regions. In Handbook of regional and urban economics (Vol. 5, pp. 625-685). Elsevier.

Peri, G. (2011). Rethinking the area approach: Immigrants and the labor market in California. Journal of International Economics, 84(1), 1-14.

Peri, G. (2016). Immigrants, productivity, and labor markets. Journal of Economic Perspectives, 30(4), 3-30.

Peri, G., \& Sparber, C. (2011). Assessing inherent model bias: An application to native displacement in response to immigration. Journal of Urban Economics, 69(1), 82-91.

Price, J., Buckles, K., Van Leeuwen, J., \& Riley, I. (2019). Combining family history and machine learning to link historical records (No. w26227). National Bureau of Economic Research.

Ruggles, S., Flood, S., Goeken, R., Grover, J., Meyer, E., Pacas, J. and Sobek, M. (2019). IPUMS USA: Version 9.0 [dataset]. Minneapolis, MN. https://doi.org/10.18128/D010.V9.0

Sequeira, S., Nunn, N., \& Qian, N. (2019). Immigrants and the Making of America. Review of Economic Studies.

Tabellini, M. (2020). Gifts of the immigrants, woes of the natives: Lessons from the age of mass migration. Review of Economic Studies, 87(1), 454-486.

vom Lehn, C., Ellsworth, C., \& Kroff, Z. (2019). Reconciling Occupational Mobility in the Current Population Survey. Working Paper.

Wozniak, A., \& Murray, T. J. (2012). Timing is everything: Short-run population impacts of immigration in US cities. Journal of Urban Economics, 72(1), 60-78. 
Table 1: Summary Statistics of Full and Linked Samples

\begin{tabular}{|c|c|c|c|c|c|c|}
\hline & \multicolumn{3}{|c|}{1910 Cohort } & \multicolumn{3}{|c|}{1920 Cohort } \\
\hline & $\begin{array}{l}\text { Full Sample } \\
\text { (1) }\end{array}$ & $\begin{array}{l}\text { Linked Sample } \\
(2)\end{array}$ & $\Delta$ Among Linked & $\begin{array}{l}\text { Full Sample } \\
\text { (4) }\end{array}$ & $\begin{array}{c}\text { Linked Sample } \\
(5)\end{array}$ & $\Delta$ Among Linked \\
\hline Age & 32.25 & 32.13 & & 33.44 & 33.20 & \\
\hline White & 0.91 & 0.94 & & 0.90 & 0.93 & \\
\hline Black & 0.09 & 0.06 & & 0.10 & 0.07 & \\
\hline Other Race & 0.00 & 0.00 & & 0.00 & 0.00 & \\
\hline In Labor Force & 0.90 & 0.90 & 0.02 & 0.87 & 0.87 & 0.06 \\
\hline Occ. Score & 27.62 & 28.38 & 0.91 & 28.02 & 28.90 & 0.42 \\
\hline Married & 0.47 & 0.55 & 0.17 & 0.52 & 0.59 & 0.18 \\
\hline Never Married & 0.49 & 0.43 & -0.20 & 0.44 & 0.38 & -0.20 \\
\hline Divorced & 0.01 & 0.00 & 0.00 & 0.01 & 0.01 & 0.01 \\
\hline No Occ. & 0.10 & 0.10 & -0.02 & 0.13 & 0.13 & -0.06 \\
\hline Farm/Farm Labor & 0.01 & 0.01 & 0.04 & 0.01 & 0.01 & 0.03 \\
\hline Other/Labor & 0.11 & 0.10 & -0.02 & 0.11 & 0.09 & -0.01 \\
\hline Services & 0.06 & 0.05 & -0.00 & 0.05 & 0.04 & 0.01 \\
\hline Clerical & 0.09 & 0.10 & -0.02 & 0.09 & 0.10 & -0.02 \\
\hline Operatives & 0.14 & 0.14 & -0.02 & 0.14 & 0.14 & -0.02 \\
\hline Sales & 0.09 & 0.09 & -0.01 & 0.08 & 0.09 & 0.02 \\
\hline Craftsmen & 0.21 & 0.23 & 0.01 & 0.22 & 0.24 & -0.01 \\
\hline Managers/Officials & 0.08 & 0.09 & 0.03 & 0.07 & 0.08 & 0.03 \\
\hline Professional/Technical & 0.05 & 0.05 & 0.02 & 0.05 & 0.06 & 0.02 \\
\hline City-level Fraction Immigrants & 0.08 & 0.08 & -0.04 & 0.04 & 0.04 & -0.02 \\
\hline City-level Immigrant Shift-Share & 0.06 & 0.06 & -0.04 & 0.03 & 0.03 & -0.01 \\
\hline Observations & $4,719,124$ & $1,814,783$ & $1,814,783$ & $5,779,699$ & $2,359,935$ & $2,359,935$ \\
\hline
\end{tabular}

Notes: Data obtained from the 1910, 1920, and 1930 full count census. Individuals are linked overtime using the Price et al. (2019) method explained in the data section. Sample restricted to men 15-65 that were born in the United States and residing in one of the 178 sample cities in 1910 or 1920 respectively. Individuals whose occupation is recorded as "Not Yet Classified" are dropped from the sample. Occ. Score is the median total income for individuals in that occupation in 1950 and more accurately captures occupational status or occupational mobility rather than earnings. 
Table 2: Fraction Moved by First Wave Age and Occupation Group

\begin{tabular}{|c|c|c|}
\hline & \multicolumn{2}{|c|}{ Fraction Moved-out } \\
\hline & $\begin{array}{c}1910 \text { to } 1920 \\
\text { (1) }\end{array}$ & $\begin{array}{c}1920 \text { to } 1930 \\
\text { (2) }\end{array}$ \\
\hline All & 0.30 & 0.34 \\
\hline $15-24$ & 0.32 & 0.35 \\
\hline $25-34$ & 0.34 & 0.37 \\
\hline $35-44$ & 0.28 & 0.33 \\
\hline $45-54$ & 0.24 & 0.31 \\
\hline $55-65$ & 0.25 & 0.32 \\
\hline No Occ. & 0.36 & 0.35 \\
\hline Farm/Farm Labor & 0.37 & 0.46 \\
\hline Other/Labor & 0.33 & 0.39 \\
\hline Services & 0.30 & 0.32 \\
\hline Clerical & 0.27 & 0.30 \\
\hline Operatives & 0.28 & 0.33 \\
\hline Sales & 0.31 & 0.36 \\
\hline Craftsmen & 0.29 & 0.34 \\
\hline Managers/Officials & 0.27 & 0.33 \\
\hline Professional/Technical & 0.30 & 0.36 \\
\hline
\end{tabular}

Notes: Data obtained from the 1910, 1920, and 1930 full count census. Individuals are linked overtime using the Price et al. (2019) method explained in the data section. Sample restricted to men 15-65 that were born in the United States and residing in one of the 178 sample cities in 1910 or 1920 respectively. Individuals whose occupation is recorded as "Not Yet Classified" are dropped from the sample. 
Table 3: City-level Impact of Immigrant Flows on Economic Outcomes of US Born Men

\begin{tabular}{|c|c|c|c|c|}
\hline & \multicolumn{2}{|c|}{ Levels Shift Share IV } & \multicolumn{2}{|c|}{ First Difference Shift Share IV } \\
\hline & $\begin{array}{l}\text { Tabellini } \\
\text { (1) }\end{array}$ & $\begin{array}{l}\text { Linkable } \\
(2)\end{array}$ & $\begin{array}{c}\text { Tabellini } \\
(3)\end{array}$ & $\begin{array}{l}\text { Linkable } \\
\text { (4) }\end{array}$ \\
\hline \multirow[b]{2}{*}{ Fraction Immigrants } & \multicolumn{4}{|c|}{ In the Labor Force (Report Gainful Occupation) } \\
\hline & $0.21^{* * *}$ & $0.18^{* * *}$ & \multirow{3}{*}{$\begin{array}{l}0.17^{* *} \\
(0.07)\end{array}$} & \multirow{3}{*}{$\begin{array}{c}0.16^{* * *} \\
(0.05)\end{array}$} \\
\hline$\Delta$ Fraction Immigrants & & & & \\
\hline & & & & \\
\hline Dependent Mean (in levels) & 0.91 & 0.86 & 0.88 & 0.85 \\
\hline Observations & 534 & 534 & 356 & 356 \\
\hline Fraction Immigrants & $\begin{array}{l}0.10^{* *} \\
(0.04)\end{array}$ & $\begin{array}{c}\log \text { Occu } \\
0.13^{* *} \\
(0.07)\end{array}$ & pation Inco & \\
\hline$\Delta$ Fraction Immigrants & & & $\begin{array}{l}0.09^{* *} \\
(0.05)\end{array}$ & $\begin{array}{c}0.11^{*} \\
(0.06)\end{array}$ \\
\hline Dependent Mean (in levels) & 3.26 & 3.35 & 3.27 & 3.35 \\
\hline Observations & 534 & 534 & 356 & 356 \\
\hline
\end{tabular}

Notes: Observation at the city level for 1910, 1920, or 1930 for 178 cities that had a population over 30,000 in each census year. Only US born men 15-65 in the initial census wave are included. Individuals whose occupation is recorded as "Not Yet Classified" are dropped from the sample. Following Tabellini (2020) New Bedford MA and Sacramento CA are excluded from the analysis. The "Tabellini" specifications use both the data and specification used by Tabellini (2020). The "Linkable" specifications construct city level measures from individuals that can be linked from one census wave to the next in the Ancestry version of the full count census. In the levels specifications city and state by year fixed effects are included. In the first difference specifications state by year fixed effects are included. Standard errors are corrected for clustering at the metropolitan area level. $\mathrm{p}<0.01^{* * *}, \mathrm{p}<0.05^{* *}, \mathrm{p}<0.1^{*}$. 
Table 4: City-level Impact of Immigrant Flows on Economic Outcomes of US Born Men, Accounting for Out-migrants

\begin{tabular}{lcc}
\hline \hline & $\Delta$ In Labor Force & $\Delta$ Log Occupation Score \\
& $(1)$ & $(2)$ \\
\hline$\Delta$ Fraction Immigrants & $0.15^{* * *}$ & -0.14 \\
& $(0.04)$ & $(0.11)$ \\
1st Wave Dependent Mean & 0.91 & 3.06 \\
Observations & 356 & 356 \\
\hline \hline
\end{tabular}

Notes: Observation at the city level for 1910 to 1920 difference or, 1920 to 1930 difference for 178 cities that had a population over 30,000 in each census year. Only US born men 15-65 in the initial census wave are included. Individuals whose occupation is recorded as "Not Yet Classified" are dropped from the sample. Following Tabellini (2020) New Bedford MA and Sacramento CA are excluded from the analysis. To construct the city level observations, each individual that can be linked from one census to the next is kept. Individuals are then assigned to the treatment of their city of residence in the initial Census wave (1910 or 1920) and then the sample is restricted to 15-64 year olds in the given Census wave. As in the unlinked city level estimates, this (1) keeps potential new entrants who were younger than 15 in the first wave, (2) excludes potential retirees who were over 54 in the first wave and would age out of the sample, (3) excludes natives that moved into the city between survey waves, and (4) includes natives that moved away from the city between survey waves. State by year fixed effects are included. Standard errors are corrected for clustering at the metropolitan area level. $\mathrm{p}<0.01{ }^{* * *}, \mathrm{p}<0.05^{* *}, \mathrm{p}<0.1^{*}$. 
Table 5: Impact of Immigrant Flows on Economic Outcomes of US Born Men, Linked Individuals

\begin{tabular}{|c|c|c|c|c|c|c|c|c|}
\hline & $\begin{array}{c}\text { Moved Out } \\
\text { (1) }\end{array}$ & $\begin{array}{c}\Delta \operatorname{In} \\
\text { Labor Force } \\
(2)\end{array}$ & $\begin{array}{c}\text { Enter LF } \\
(3)\end{array}$ & $\begin{array}{l}\text { Exit LF } \\
(4)\end{array}$ & $\begin{array}{c}\Delta \text { Log Occ. } \\
\text { Score } \\
(5)\end{array}$ & $\begin{array}{c}\Delta \text { Occ. } \\
(6)\end{array}$ & $\begin{array}{c}\Delta \text { Log Occ. } \\
\text { Score }>0 \\
(7)\end{array}$ & $\begin{array}{c}\Delta \log \text { Occ. } \\
\text { Score }<0 \\
(8)\end{array}$ \\
\hline$\Delta$ Fraction Immigrants & $\begin{array}{l}0.57^{* *} \\
(0.26)\end{array}$ & $\begin{array}{c}0.22^{* * *} \\
(0.06)\end{array}$ & $\begin{array}{c}0.13^{* * *} \\
(0.05)\end{array}$ & $\begin{array}{c}-0.09 * * * \\
(0.02)\end{array}$ & $\begin{array}{c}-0.06 \\
(0.05)\end{array}$ & $\begin{array}{c}-0.30^{* * *} \\
(0.10)\end{array}$ & $\begin{array}{c}-0.06 \\
(0.06)\end{array}$ & $\begin{array}{c}-0.22^{* * *} \\
(0.06)\end{array}$ \\
\hline Dependent Mean & 0.32 & 0.89 & 0.10 & 0.06 & 3.30 & 0.51 & 0.33 & 0.28 \\
\hline Observations & $4,150,273$ & $3,954,889$ & $3,954,889$ & $3,954,889$ & $3,291,188$ & $3,291,188$ & $3,291,188$ & $3,291,188$ \\
\hline
\end{tabular}

Notes: Sample includes all US born men 15 to 65 that can be linked across two census waves: 1910 to 1920 and 1920 to 1930 . Only individuals who were in one of the 178 cities in the year are included. Individuals whose occupation is recorded as "Not Yet Classified" are dropped from the sample. Because it is estimated in a first difference, only one observation per person is included. Following Tabellini (2020) New Bedford MA and Sacramento CA are excluded from the analysis. State by year fixed effects are included. Age fixed effects are also included to compare same-aged people across cities. Standard errors are corrected for clustering at the metropolitan area level. $\mathrm{p}<0.01 * * *, \mathrm{p}<0.05^{* *}, \mathrm{p}<0.1^{*}$. 
Table 6: Impact of Immigrant Flows on Occupational Mobility of US Born Men, Linked Individuals

\begin{tabular}{|c|c|c|c|c|c|c|c|c|c|}
\hline & \multicolumn{9}{|c|}{$\Delta$ Log Occ. Score } \\
\hline & \multicolumn{4}{|c|}{ Decrease in Log Occ. Score } & \multirow[b]{2}{*}{$\begin{array}{c}0 \\
(5)\end{array}$} & \multicolumn{4}{|c|}{ Increase in Log Occ. Score } \\
\hline & $\begin{array}{c}>0.75 \\
(1)\end{array}$ & $\begin{array}{c}0.75-0.5 \\
(2)\end{array}$ & $\begin{array}{c}0.5-0.25 \\
(3)\end{array}$ & $\begin{array}{c}0.25-0 \\
(4)\end{array}$ & & $\begin{array}{c}0-0.25 \\
(6)\end{array}$ & $\begin{array}{c}0.25-0.5 \\
(7)\end{array}$ & $\begin{array}{c}0.5-0.75 \\
(8)\end{array}$ & $\begin{array}{c}>0.75 \\
(9)\end{array}$ \\
\hline$\Delta$ Fraction Immigrants & $\begin{array}{c}0.09 * * * \\
(0.02)\end{array}$ & $\begin{array}{c}-0.06^{* * *} \\
(0.02)\end{array}$ & $\begin{array}{c}0.01 \\
(0.03)\end{array}$ & $\begin{array}{c}-0.25^{* * *} \\
(0.04)\end{array}$ & $\begin{array}{c}0.28^{* * *} \\
(0.10)\end{array}$ & $\begin{array}{c}0.01 \\
(0.02)\end{array}$ & $\begin{array}{c}0.04 \\
(0.03)\end{array}$ & $\begin{array}{c}-0.11^{* * *} \\
(0.03)\end{array}$ & $\begin{array}{c}-0.01 \\
(0.03)\end{array}$ \\
\hline Dependent Mean & 0.03 & 0.05 & 0.08 & 0.12 & 0.39 & 0.13 & 0.10 & 0.08 & 0.03 \\
\hline Observations & $3,291,188$ & $3,291,188$ & $3,291,188$ & $3,291,188$ & $3,291,188$ & $3,291,188$ & $3,291,188$ & $3,291,188$ & $3,291,188$ \\
\hline
\end{tabular}

Notes: Sample includes all US born men 15 to 65 that can be linked across two census waves: 1910 to 1920 and 1920 to 1930 . Only individuals who were in one of the 178 cities in the year are included. Individuals whose occupation is recorded as "Not Yet Classified" are dropped from the sample. Because it is estimated in a first difference, only one observation per person is included. Following Tabellini (2020) New Bedford MA and Sacramento CA are excluded from the analysis. State by year fixed effects are included. Age fixed effects are also included to compare same-aged people across cities. Standard errors are corrected for clustering at the metropolitan area level. $\mathrm{p}<0.01^{* * *}, \mathrm{p}<0.05^{* *}, \mathrm{p}<0.1^{*}$. 
Table 7: Heterogeneous Impacts by Age of Immigrant Flows on Economic Outcomes of US Born Men, Linked Individuals

\begin{tabular}{|c|c|c|c|c|c|c|c|c|}
\hline & $\begin{array}{l}\text { Moved Out } \\
\text { (1) }\end{array}$ & $\begin{array}{c}\Delta \operatorname{In} \\
\text { Labor Force } \\
(2)\end{array}$ & $\begin{array}{c}\text { Enter LF } \\
(3)\end{array}$ & $\begin{array}{l}\text { Exit LF } \\
(4)\end{array}$ & $\begin{array}{c}\Delta \text { Log Occ. } \\
\text { Score } \\
(5)\end{array}$ & $\begin{array}{c}\Delta \text { Occ. } \\
(6)\end{array}$ & $\begin{array}{c}\Delta \text { Log Occ. } \\
\text { Score }>0 \\
(7)\end{array}$ & $\begin{array}{c}\Delta \text { Log Occ. } \\
\text { Score }<0 \\
(8)\end{array}$ \\
\hline$\Delta$ Fraction Immigrants*Age $15-24$ & $\begin{array}{c}0.91^{* * *} \\
(0.31)\end{array}$ & $\begin{array}{c}0.78 * * * \\
(0.13)\end{array}$ & $\begin{array}{c}0.66^{* * *} \\
(0.10)\end{array}$ & $\begin{array}{c}-0.13^{* * *} \\
(0.04)\end{array}$ & $\begin{array}{c}-0.17^{* * *} \\
(0.06)\end{array}$ & $\begin{array}{c}-0.35^{* * * *} \\
(0.10)\end{array}$ & $\begin{array}{c}-0.20^{* *} \\
(0.08)\end{array}$ & $\begin{array}{c}-0.20^{* * *} \\
(0.05)\end{array}$ \\
\hline$\Delta$ Fraction Immigrants*Age $25-34$ & $\begin{array}{l}0.54^{* *} \\
(0.26)\end{array}$ & $\begin{array}{c}0.01 \\
(0.06)\end{array}$ & $\begin{array}{l}-0.11^{*} \\
(0.06)\end{array}$ & $\begin{array}{c}-0.12^{* * *} \\
(0.03)\end{array}$ & $\begin{array}{c}-0.01 \\
(0.05)\end{array}$ & $\begin{array}{c}-0.33^{* * *} \\
(0.11)\end{array}$ & $\begin{array}{c}0.02 \\
(0.07)\end{array}$ & $\begin{array}{c}-0.27^{* * *} \\
(0.07)\end{array}$ \\
\hline$\Delta$ Fraction Immigrants*Age $35-44$ & $\begin{array}{c}0.35 \\
(0.25)\end{array}$ & $\begin{array}{c}-0.05 \\
(0.06)\end{array}$ & $\begin{array}{c}-0.16^{* * *} \\
(0.05)\end{array}$ & $\begin{array}{c}-0.11^{* * *} \\
(0.03)\end{array}$ & $\begin{array}{c}-0.05 \\
(0.05)\end{array}$ & $\begin{array}{c}-0.31^{* * *} \\
(0.10)\end{array}$ & $\begin{array}{c}-0.08 \\
(0.07)\end{array}$ & $\begin{array}{c}-0.19^{* * *} \\
(0.06)\end{array}$ \\
\hline$\Delta$ Fraction Immigrants* Age $45-54$ & $\begin{array}{c}0.26 \\
(0.25)\end{array}$ & $\begin{array}{c}-0.08 \\
(0.09)\end{array}$ & $\begin{array}{c}-0.19^{* * *} \\
(0.06)\end{array}$ & $\begin{array}{l}-0.11^{*} \\
(0.06)\end{array}$ & $\begin{array}{c}0.06 \\
(0.06)\end{array}$ & $\begin{array}{l}-0.19^{*} \\
(0.11)\end{array}$ & $\begin{array}{c}0.07 \\
(0.10)\end{array}$ & $\begin{array}{c}-0.24^{* * *} \\
(0.07)\end{array}$ \\
\hline$\Delta$ Fraction Immigrants*Age 55-65 & $\begin{array}{c}0.00 \\
(0.26)\end{array}$ & $\begin{array}{c}-0.74^{* * * *} \\
(0.18)\end{array}$ & $\begin{array}{c}-0.29 * * * \\
(0.06)\end{array}$ & $\begin{array}{c}0.45^{* * *} \\
(0.14)\end{array}$ & $\begin{array}{c}0.06 \\
(0.06)\end{array}$ & $\begin{array}{c}-0.01 \\
(0.15)\end{array}$ & $\begin{array}{c}0.05 \\
(0.12)\end{array}$ & $\begin{array}{c}-0.11 \\
(0.07)\end{array}$ \\
\hline Dependent Mean & 0.32 & 0.89 & 0.10 & 0.06 & 3.30 & 0.51 & 0.33 & 0.28 \\
\hline Observations & $4,150,273$ & $3,954,889$ & $3,954,889$ & $3,954,889$ & $3,291,188$ & $3,291,188$ & $3,291,188$ & $3,291,188$ \\
\hline
\end{tabular}

Notes: Sample includes all US born men 15 to 65 that can be linked across two census waves: 1910 to 1920 and 1920 to 1930 . Only individuals who were in one of the 178 cities in the year are included. Individuals whose occupation is recorded as "Not Yet Classified" are dropped from the sample. Because it is estimated in a first difference, only one observation per person is included. Following Tabellini (2020) New Bedford MA and Sacramento CA are excluded from the analysis. State by year fixed effects are included. Age fixed effects are also included to compare same-aged people across cities. Standard errors are corrected for clustering at the metropolitan area level. $\mathrm{p}<0.01^{* * *}, \mathrm{p}<0.05^{* *}, \mathrm{p}<0.1^{*}$. 
Table 8: Heterogeneous Impacts by Initial Occupation of Immigrant Flows on Economic Outcomes of US Born Men, Linked Individuals

\begin{tabular}{|c|c|c|c|c|c|c|}
\hline & $\begin{array}{l}\text { Moved Out } \\
\text { (1) }\end{array}$ & $\begin{array}{c}\Delta \text { In } \\
\text { Labor Force } \\
\quad(2)\end{array}$ & $\begin{array}{c}\Delta \text { Log Occ. } \\
\text { Score } \\
(3)\end{array}$ & $\begin{array}{c}\Delta \text { Occ. } \\
(4)\end{array}$ & $\begin{array}{c}\Delta \text { Log Occ. } \\
\text { Score }>0 \\
(5)\end{array}$ & $\begin{array}{c}\Delta \text { Log Occ. } \\
\text { Score }<0 \\
(6)\end{array}$ \\
\hline$\Delta$ Fraction Immigrants*No Occ. & $\begin{array}{c}0.34 \\
(0.27)\end{array}$ & $\begin{array}{c}0.27^{* * *} \\
(0.10)\end{array}$ & & & & \\
\hline$\Delta$ Fraction Immigrants*Farm/Farm Labor & $\begin{array}{c}1.17^{* * *} \\
(0.40)\end{array}$ & $\begin{array}{c}0.13 \\
(0.11)\end{array}$ & $\begin{array}{c}-2.09^{* * *} \\
(0.56)\end{array}$ & $\begin{array}{c}-2.24^{* * *} \\
(0.71)\end{array}$ & $\begin{array}{l}-1.35^{* *} \\
(0.57)\end{array}$ & $\begin{array}{c}-0.51^{* * *} \\
(0.10)\end{array}$ \\
\hline$\Delta$ Fraction Immigrants* Other/Labor & $\begin{array}{c}1.48^{* * *} \\
(0.37)\end{array}$ & $\begin{array}{c}0.03 \\
(0.04)\end{array}$ & $\begin{array}{c}-1.12^{\text {*** }} \\
(0.26)\end{array}$ & $\begin{array}{c}-0.70^{* *} \\
(0.32)\end{array}$ & $\begin{array}{c}-1.45^{* * * *} \\
(0.33)\end{array}$ & $\begin{array}{c}0.38^{* * *} \\
(0.15)\end{array}$ \\
\hline$\Delta$ Fraction Immigrants*Services & $\begin{array}{l}0.54^{* *} \\
(0.24)\end{array}$ & $\begin{array}{l}0.09 * * \\
(0.04)\end{array}$ & $\begin{array}{c}0.60^{* * *} \\
(0.15)\end{array}$ & $\begin{array}{c}-0.88^{* * *} \\
(0.22)\end{array}$ & $\begin{array}{c}0.25 \\
(0.16)\end{array}$ & $\begin{array}{c}-0.96^{* * *} \\
(0.24)\end{array}$ \\
\hline$\Delta$ Fraction Immigrants $*$ Clerical & $\begin{array}{c}0.10 \\
(0.25)\end{array}$ & $\begin{array}{c}0.10^{* * *} \\
(0.03)\end{array}$ & $\begin{array}{l}-0.05 \\
(0.08)\end{array}$ & $\begin{array}{l}-0.18 \\
(0.13)\end{array}$ & $\begin{array}{l}-0.16^{*} \\
(0.09)\end{array}$ & $\begin{array}{c}-0.31^{* * *} \\
(0.12)\end{array}$ \\
\hline$\Delta$ Fraction Immigrants $*$ Operative & $\begin{array}{c}0.85^{* * *} \\
(0.32)\end{array}$ & $\begin{array}{c}0.05 \\
(0.03)\end{array}$ & $\begin{array}{l}-0.09 \\
(0.11)\end{array}$ & $\begin{array}{l}-0.16 \\
(0.17)\end{array}$ & $\begin{array}{l}-0.16 \\
(0.15)\end{array}$ & $\begin{array}{c}-0.24 \\
(0.21)\end{array}$ \\
\hline$\Delta$ Fraction Immigrants*Sales & $\begin{array}{c}0.41 \\
(0.26)\end{array}$ & $\begin{array}{l}0.07^{* *} \\
(0.03)\end{array}$ & $\begin{array}{c}0.40^{* * *} \\
(0.08)\end{array}$ & $\begin{array}{c}-0.85^{* * * *} \\
(0.22)\end{array}$ & $\begin{array}{l}0.18^{* *} \\
(0.08)\end{array}$ & $\begin{array}{c}-0.76^{\text {*** }} \\
(0.18)\end{array}$ \\
\hline$\Delta$ Fraction Immigrants ${ }^{*}$ Craftsmen & $\begin{array}{l}0.64^{* *} \\
(0.25)\end{array}$ & $\begin{array}{l}-0.01 \\
(0.04)\end{array}$ & $\begin{array}{l}0.19^{* *} \\
(0.08)\end{array}$ & $\begin{array}{c}0.20 \\
(0.16)\end{array}$ & $\begin{array}{c}0.39^{* * *} \\
(0.08)\end{array}$ & $\begin{array}{l}-0.20 \\
(0.13)\end{array}$ \\
\hline$\Delta$ Fraction Immigrants*Manager/Official & $\begin{array}{c}0.17 \\
(0.25)\end{array}$ & $\begin{array}{l}0.09^{* *} \\
(0.04)\end{array}$ & $\begin{array}{c}0.42^{* * *} \\
(0.08)\end{array}$ & $\begin{array}{c}-0.46^{* * * *} \\
(0.12)\end{array}$ & $\begin{array}{c}0.34^{* * *} \\
(0.07)\end{array}$ & $\begin{array}{c}-0.80^{* * *} \\
(0.15)\end{array}$ \\
\hline$\Delta$ Fraction Immigrants*Professional/Technical & $\begin{array}{c}0.36 \\
(0.27)\end{array}$ & $\begin{array}{l}0.06 \\
(0.04)\end{array}$ & $\begin{array}{c}0.28^{* * *} \\
(0.08)\end{array}$ & $\begin{array}{c}-0.13 \\
(0.12)\end{array}$ & $\begin{array}{c}0.34^{* * *} \\
(0.07)\end{array}$ & $\begin{array}{c}-0.52^{* * *} \\
(0.17)\end{array}$ \\
\hline $\begin{array}{l}\text { Dependent Mean } \\
\text { Observations }\end{array}$ & $\begin{array}{c}0.32 \\
4,150,273\end{array}$ & $\begin{array}{c}0.89 \\
3,954,889\end{array}$ & $\begin{array}{c}3.30 \\
3,291,188\end{array}$ & $\begin{array}{c}0.51 \\
3,291,188\end{array}$ & $\begin{array}{c}0.33 \\
3,291,188\end{array}$ & $\begin{array}{c}0.28 \\
3,291,188\end{array}$ \\
\hline
\end{tabular}

Notes: Sample includes all US born men 15 to 65 that can be linked across two census waves: 1910 to 1920 and 1920 to 1930 . Only individuals who were in one of the 178 cities in the year are included. Individuals whose occupation is recorded as "Not Yet Classified" are dropped from the sample. Because it is estimated in a first difference, only one observation per person is included. Following Tabellini (2020) New Bedford MA and Sacramento CA are excluded from the analysis. State by year fixed effects are included. Age fixed effects are also included to compare same-aged people across cities. "Not Yet Classified" occupations are occupation strings that occur rarely in the original Census files and have not been classified into an occupation yet. Standard errors are corrected for clustering at the metropolitan area level. $\mathrm{p}<0.01^{* * *}, \mathrm{p}<0.05^{* *}, \mathrm{p}<0.1^{*}$. 
Table 9: Heterogeneous Impacts by Migration Status of Immigrant Flows on Economic Outcomes of US Born Men, Linked Individuals

\begin{tabular}{|c|c|c|c|c|c|c|c|}
\hline & $\begin{array}{c}\Delta \operatorname{In} \\
\text { Labor Force } \\
(1)\end{array}$ & $\begin{array}{c}\text { Enter LF } \\
(2)\end{array}$ & $\begin{array}{c}\text { Exit LF } \\
(3)\end{array}$ & $\begin{array}{c}\Delta \text { Log Occ. } \\
\text { Score } \\
(4)\end{array}$ & $\begin{array}{c}\Delta \text { Occ. } \\
(5)\end{array}$ & $\begin{array}{c}\Delta \text { Log Occ. } \\
\text { Score }>0 \\
(6)\end{array}$ & $\begin{array}{c}\Delta \text { Log Occ. } \\
\text { Score }<0 \\
(7)\end{array}$ \\
\hline$\Delta$ Fraction Immigrants*Stayer & $\begin{array}{l}0.17^{* * *} \\
(0.06)\end{array}$ & $\begin{array}{l}0.12 * * \\
(0.05)\end{array}$ & $\begin{array}{l}-0.05^{*} \\
(0.03)\end{array}$ & $\begin{array}{l}0.12^{* *} \\
(0.05)\end{array}$ & $\begin{array}{c}-0.50^{* * * *} \\
(0.11)\end{array}$ & $\begin{array}{c}-0.01 \\
(0.07)\end{array}$ & $\begin{array}{c}-0.47^{* * * *} \\
(0.07)\end{array}$ \\
\hline$\Delta$ Fraction Immigrants* Move-out & $\begin{array}{c}0.35^{* * *} \\
(0.07)\end{array}$ & $\begin{array}{l}0.13^{* *} \\
(0.06)\end{array}$ & $\begin{array}{c}-0.22^{* * *} \\
(0.05)\end{array}$ & $\begin{array}{c}-0.32^{* * *} \\
(0.11)\end{array}$ & $\begin{array}{l}-0.16 \\
(0.13)\end{array}$ & $\begin{array}{c}-0.24^{* * *} \\
(0.09)\end{array}$ & $\begin{array}{c}0.09 \\
(0.13)\end{array}$ \\
\hline Move-out & $\begin{array}{l}-0.00 \\
(0.00)\end{array}$ & $\begin{array}{c}0.01^{* * *} \\
(0.00)\end{array}$ & $\begin{array}{c}0.02^{* * *} \\
(0.00)\end{array}$ & $\begin{array}{c}-0.11^{* * *} \\
(0.01)\end{array}$ & $\begin{array}{c}0.21^{* * *} \\
(0.01)\end{array}$ & $\begin{array}{c}0.02^{* * *} \\
(0.01)\end{array}$ & $\begin{array}{c}0.18^{* * *} \\
(0.01)\end{array}$ \\
\hline $\begin{array}{l}\text { Dependent Mean } \\
\text { Observations }\end{array}$ & $\begin{array}{c}0.89 \\
3,954,889\end{array}$ & $\begin{array}{c}0.10 \\
3,954,889\end{array}$ & $\begin{array}{c}0.06 \\
3,954,889\end{array}$ & $\begin{array}{c}3.30 \\
3,291,188\end{array}$ & $\begin{array}{c}0.51 \\
3,291,188\end{array}$ & $\begin{array}{c}0.33 \\
3,291,188\end{array}$ & $\begin{array}{c}0.28 \\
3,291,188\end{array}$ \\
\hline
\end{tabular}

Notes: Sample includes all US born men 15 to 65 that can be linked across two census waves: 1910 to 1920 and 1920 to 1930 . Only individuals who were in one of the 178 cities in the year are included. Individuals whose occupation is recorded as "Not Yet Classified" are dropped from the sample. Because it is estimated in a first difference, only one observation per person is included. Following Tabellini (2020) New Bedford MA and Sacramento CA are excluded from the analysis. State by year fixed effects are included. Age fixed effects are also included to compare same-aged people across cities. "Not Yet Classified" occupations are occupation strings that occur rarely in the original Census files and have not been classified into an occupation yet. Standard errors are corrected for clustering at the metropolitan area level. $\mathrm{p}<0.01^{* * *}, \mathrm{p}<0.05^{* *}, \mathrm{p}<0.1^{*}$. 
Table 10: Do US Born Men that Move-out Move to Avoid Immigrants?

\begin{tabular}{|c|c|c|c|c|}
\hline & $\begin{array}{l}\text { Move to } \mathrm{Ci} \\
\text { Quartile } 1 \\
(1)\end{array}$ & $\begin{array}{c}\text { y with Frac } \\
\text { Quartile } 2 \\
(2)\end{array}$ & $\begin{array}{c}\text { ion Recent } \\
\text { Quartile } 3 \\
(3)\end{array}$ & $\begin{array}{c}\text { migrants in } \\
\text { Quartile } 4 \\
(4)\end{array}$ \\
\hline$\Delta$ Fraction Immigrants & $\begin{array}{c}0.09 \\
(0.06)\end{array}$ & $\begin{array}{c}0.10 \\
(0.07)\end{array}$ & $\begin{array}{c}0.24^{*} \\
(0.14)\end{array}$ & $\begin{array}{c}0.06 \\
(0.15)\end{array}$ \\
\hline Dependent Mean & 0.07 & 0.08 & 0.09 & 0.08 \\
\hline Observations & $4,155,506$ & $4,155,506$ & $4,155,506$ & $4,155,506$ \\
\hline
\end{tabular}

Notes: Sample includes all US born men 15 to 65 that can be linked across two census waves: 1910 to 1920 and 1920 to 1930 and that moved cities between waves. Only individuals who were in one of the 178 cities in the year are included. Individuals whose occupation is recorded as "Not Yet Classified" are dropped from the sample. Because it is estimated in a first difference, only one observation per person is included. Following Tabellini (2020) New Bedford MA and Sacramento $\mathrm{CA}$ are excluded from the analysis. State by year fixed effects are included. Age fixed effects are also included to compare same-aged people across cities. Standard errors are corrected for clustering at the metropolitan area level. $\mathrm{p}<0.01^{* * *}, \mathrm{p}<0.05^{* *}, \mathrm{p}<0.1^{*}$. 
Table 11: Impact of Immigrant Flows on Economic Outcomes of Potential New Entrants US Born Men, Linked Individuals

\begin{tabular}{lccc}
\hline \hline & $\begin{array}{c}\text { Moved Out } \\
(1)\end{array}$ & $\begin{array}{c}\text { In Labor Force } \\
(2)\end{array}$ & $\begin{array}{c}\text { Log Occ. Score } \\
(3)\end{array}$ \\
\hline$\Delta$ Fraction Immigrants & $0.57^{*}$ & $-0.48^{* * *}$ & -0.22 \\
& $(0.30)$ & $(0.15)$ & $(0.16)$ \\
Dependent Mean & 0.23 & 0.59 & 3.17 \\
Observations & $2,253,490$ & $2,201,242$ & $1,291,562$ \\
\hline \hline
\end{tabular}

Notes: Sample includes all US born men 5 to 14 in the initial wave that can be linked across two census waves: 1910 to 1920 and 1920 to 1930 . Only individuals who were in one of the 178 cities in the year are included. Individuals whose occupation is recorded as "Not Yet Classified" are dropped from the sample. Because it is estimated in a first difference, only one observation per person is included. Following Tabellini (2020) New Bedford MA and Sacramento CA are excluded from the analysis. State by year fixed effects are included. Age fixed effects are also included to compare same-aged people across cities. Standard errors are corrected for clustering at the metropolitan area level. $\mathrm{p}<0.01^{* * *}, \mathrm{p}<0.05^{* *}, \mathrm{p}<0.1^{*}$. 
Table 12: Heterogeneous Impact by Migration Status of Immigrant Flows on Economic Outcomes of US Born Men Non-Movers and Move-ins, Linked Individuals

\begin{tabular}{|c|c|c|c|c|c|c|c|c|}
\hline & $\begin{array}{l}\text { Moved In } \\
\quad(1)\end{array}$ & $\begin{array}{c}\Delta \text { In } \\
\text { Labor Force } \\
(2)\end{array}$ & $\begin{array}{c}\text { Enter LF } \\
\quad(3)\end{array}$ & $\begin{array}{c}\text { Exit LF } \\
(4)\end{array}$ & $\begin{array}{c}\Delta \text { Log Occ. } \\
\text { Score } \\
(5)\end{array}$ & $\begin{array}{c}\Delta \text { Occ. } \\
(6)\end{array}$ & $\begin{array}{c}\Delta \text { Log Occ. } \\
\text { Score }>0 \\
(7)\end{array}$ & $\begin{array}{c}\Delta \text { Log Occ. } \\
\text { Score }<0 \\
(8)\end{array}$ \\
\hline$\Delta$ Fraction Immigrants & $\begin{array}{c}1.85^{* * *} \\
(0.34)\end{array}$ & & & & & & & \\
\hline$\Delta$ Fraction Immigrants* Stayer & & $\begin{array}{c}0.10^{*} \\
(0.06)\end{array}$ & $\begin{array}{c}0.04 \\
(0.05)\end{array}$ & $\begin{array}{c}-0.06 \\
(0.04)\end{array}$ & $\begin{array}{c}0.10 \\
(0.08)\end{array}$ & $\begin{array}{c}-0.62^{* * *} \\
(0.11)\end{array}$ & $\begin{array}{c}-0.16^{*} \\
(0.08)\end{array}$ & $\begin{array}{c}-0.41^{* * *} \\
(0.08)\end{array}$ \\
\hline$\Delta$ Fraction Immigrants* Move-in & & $\begin{array}{c}-0.09 \\
(0.09)\end{array}$ & $\begin{array}{c}-0.07 \\
(0.07)\end{array}$ & $\begin{array}{c}0.02 \\
(0.06)\end{array}$ & $\begin{array}{c}1.25^{* * *} \\
(0.19)\end{array}$ & $\begin{array}{c}0.02 \\
(0.18)\end{array}$ & $\begin{array}{c}0.76^{* * *} \\
(0.18)\end{array}$ & $\begin{array}{c}-0.91^{* * *} \\
(0.12)\end{array}$ \\
\hline Move-in & & $\begin{array}{l}0.01^{* *} \\
(0.00)\end{array}$ & $\begin{array}{c}0.02^{* * *} \\
(0.00)\end{array}$ & $\begin{array}{c}0.01^{* * *} \\
(0.00)\end{array}$ & $\begin{array}{c}0.21^{* * *} \\
(0.01)\end{array}$ & $\begin{array}{c}0.25^{* * *} \\
(0.01)\end{array}$ & $\begin{array}{c}0.22^{* * *} \\
(0.01)\end{array}$ & $\begin{array}{c}0.01 \\
(0.01)\end{array}$ \\
\hline Dependent Mean & 0.39 & 0.87 & 0.11 & 0.05 & 3.21 & 0.54 & 0.40 & 0.23 \\
\hline Observations & $4,476,173$ & $4,269,028$ & $4,269,028$ & $4,269,028$ & $3,493,540$ & $3,493,540$ & $3,493,540$ & $3,493,540$ \\
\hline
\end{tabular}

Notes: Sample includes all US born men 15 to 65 that can be linked across two census waves: 1910 to 1920 and 1920 to 1930 . Only individuals who were in one of the 178 cities in the year are included. Individuals whose occupation is recorded as "Not Yet Classified" are dropped from the sample. Because it is estimated in a first difference, only one observation per person is included. Following Tabellini (2020) New Bedford MA and Sacramento CA are excluded from the analysis. State by year fixed effects are included. Age fixed effects are also included to compare same-aged people across cities. Treatment is assigned based on place of residence in the second census wave, so we are observing those that did not move and those that moved-in. Standard errors are corrected for clustering at the metropolitan area level. $\mathrm{p}<0.01^{* * *}, \mathrm{p}<0.05^{* *}, \mathrm{p}<0.1^{*}$. 
Table 13: Selection of US Born Migrants: Relationship Between Fraction Immigrants and Baseline Characteristics of US Born Outand In-Migrants

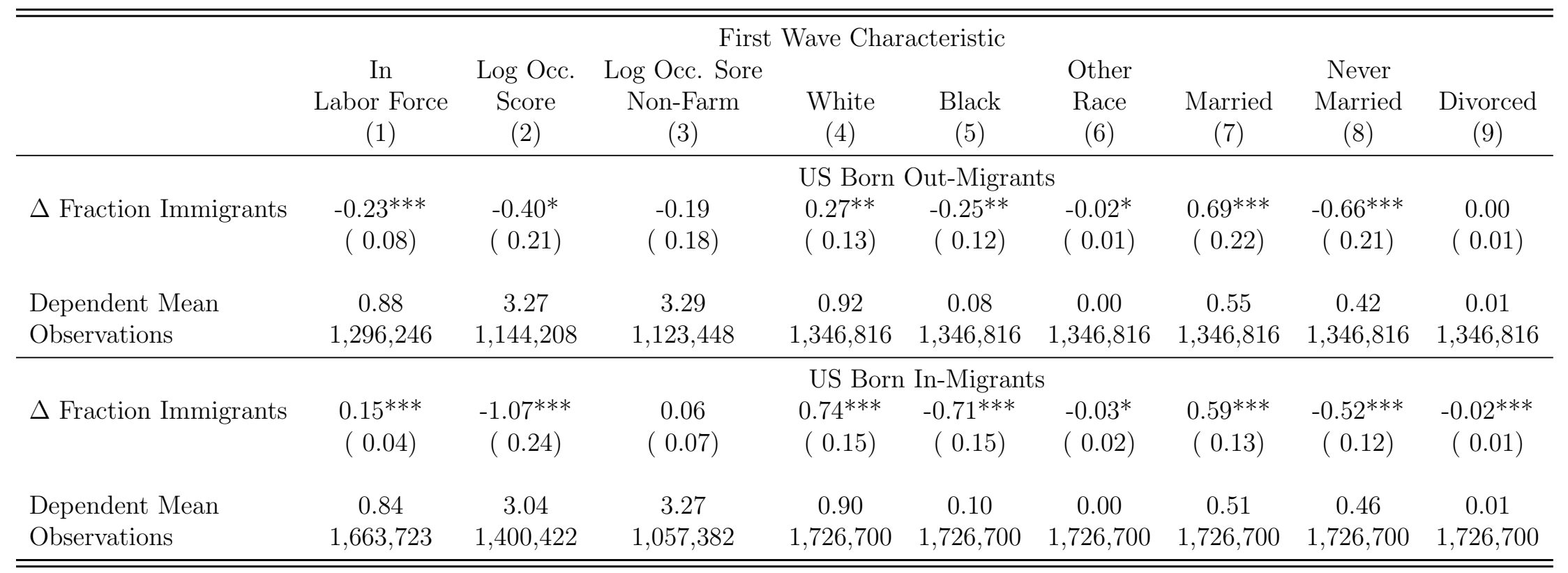

Notes: Sample includes all US born men 15 to 65 that can be linked across two census waves: 1910 to 1920 and 1920 to 1930 and that moved cities between waves. Only individuals who were in one of the 178 cities in the year are included. Individuals whose occupation is recorded as "Not Yet Classified" are dropped from the sample. Because it is estimated in a first difference, only one observation per person is included. Following Tabellini (2020) New Bedford MA and Sacramento CA are excluded from the analysis. State by year fixed effects are included. Age fixed effects are also included to compare same-aged people across cities. Standard errors are corrected for clustering at the metropolitan area level. $\mathrm{p}<0.01^{* * *}, \mathrm{p}<0.05^{* *}, \mathrm{p}<0.1^{*}$. 

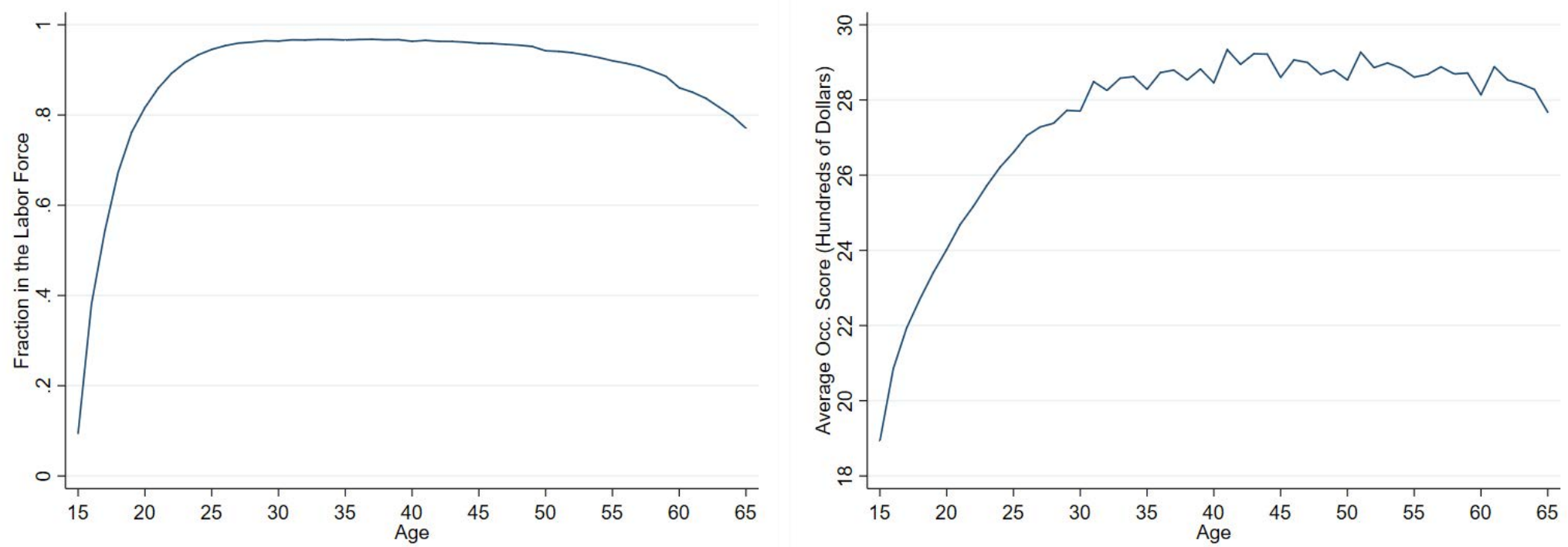

Figure 1: Labor Force Participation and Occupation Score Life-cycle Profile for US Born Men

Notes: Data obtained from the 1910, 1920, and 1930 full count census. Sample restricted to men 15-65 that are born in the US. Individuals whose occupation is recorded as "Not Yet Classified" are dropped from the sample. The Occupation Score is the median total income (in hundreds of 1950 dollars) of all people with that occupation.

Source: Author's own calculations. 


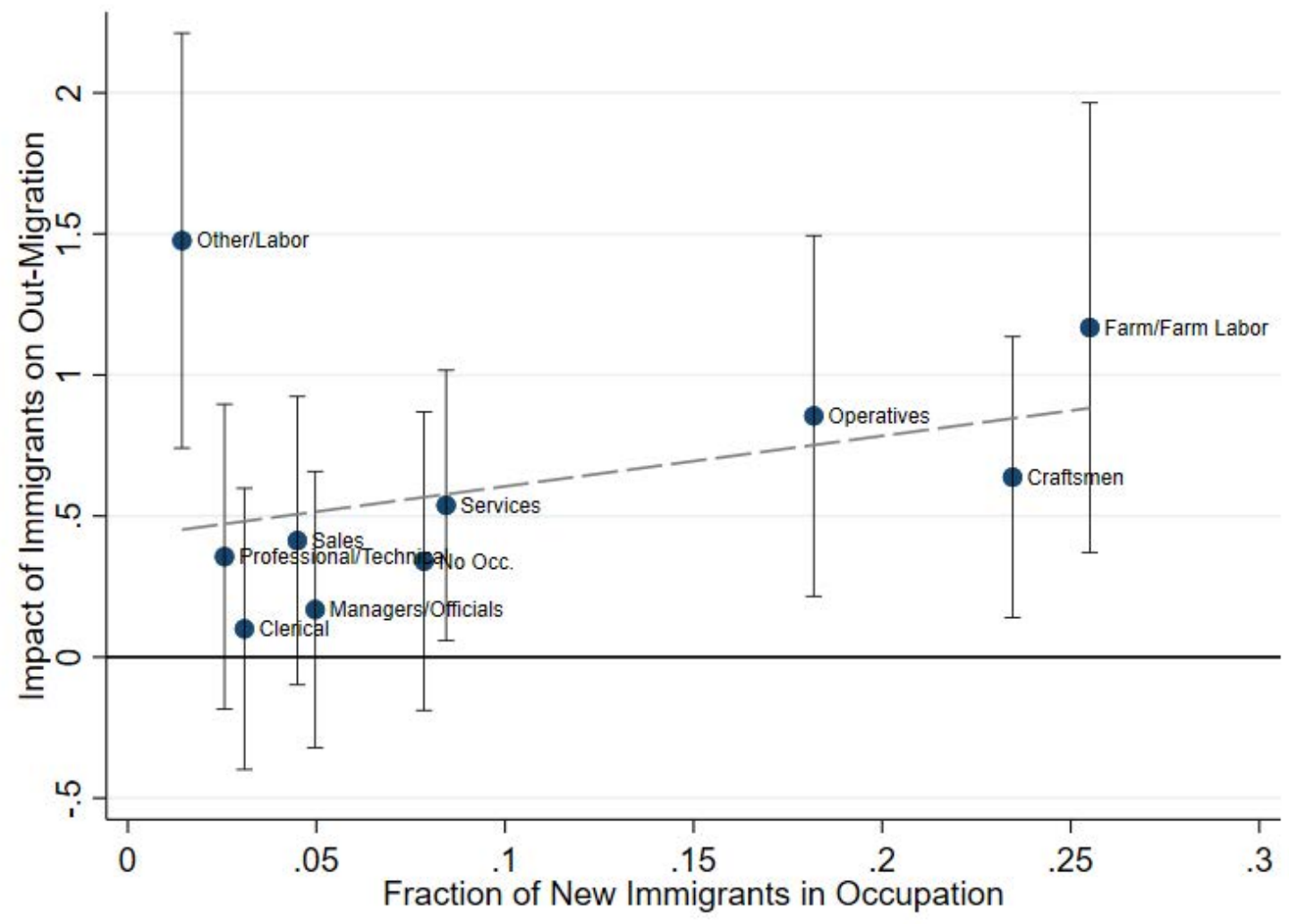

Figure 2: Potential Displacement: New Immigrant Occupations and Out-Migration Responses

Notes: Data for the fraction of new immigrants obtained from the 1920 and 1930 full count census. Sample is restricted to male immigrants 15-65 that arrived to the United States within the last ten years. Individuals whose occupation is recorded as "Not Yet Classified" are dropped from the sample. Impacts on out-migration are the coefficients from Table 7.

Source: Author's own calculations. 